\title{
TREVIÑO: ENTRE LA RESERVA ESTATUTARIA Y LA LEY ORGÁNICA
}

\author{
MANUEL CABANAS VEIGA
}


SUMARIO

I. INTRODUCCIÓN. II. PLANTEAMIENTO DE LA PROBLEMÁTICA CONSTITUCIONAL EN ATENCIÓN AL CASO CONCRETO. III. PROPUESTAS Y RESOLUCIÓN PARLAMENTARIA. IV. ¿REFORMA ESTATUTARIA O LEY ORGÁNICA? V. CONCLUSIÓN. 


\title{
TREVIÑO: ENTRE LA RESERVA ESTATUTARIA Y LA LEY ORGÁNICA
}

\author{
MANUEL CABANAS VEIGA \\ Investigador predoctoral. Área de Derecho constitucional \\ Universidade da Coruña
}

\section{INTRODUCCIÓN}

No habrá lector que, ante los siguientes hechos, pueda quedar indiferente, a saber: Que en plena época globalizadora, cuando se intenta acabar con las fronteras y romper con los Estados, aparece también un fuerte movimiento particularizante que defiende mantener un romántico sentimiento local, natural para unos y artificial para otros. Así, al mismo tiempo, las personas se sienten más ciudadanos del mundo y, a la vez, más miembros de su comunidad o, como expone el Profesor De Vega, «Diríase que nos hallamos condenados a desarrollar nuestra existencia en la esquizofrenia de dos utopías antagónicas (la utopía de la cosmopolitización y la utopía del localismo) que terminan generando realidades contradictorias y excluyentes ${ }^{1} »$.

$\mathrm{Y}$ es, precisamente, en ese avatar identitario donde se encuentra nuestro objeto de estudio. Así, el Enclave de Treviño está conformado por los municipios del Condado de Treviño y La Puebla de Arganzón. Dicho enclave se encuentra inserto geográficamente en la provincia de Álava pero, jurídicamente, pertenece a la provincia de Burgos. De esta forma, dicho enclave se encuentra a $100 \mathrm{~km}$ de Burgos y a $15 \mathrm{~km}$ de Vitoria, contando el primero con siete concejales y el segundo con cinco. Hasta aquí podría parecer que el trabajo aquí presentado

1 De Vega García, P., «En torno a la crisis de las ideas de representación y de legitimidad en la democracia actual», Temas de Derecho Público 42, Universidad Externado de Colombia, Bogota, 1996, cit., p. 12. 
carece de relevancia constitucional, pero sacados estos datos, todo lo políticamente relativo a Treviño es polémico, incluso hasta su toponimia. Así, hay quien sostiene que Treviño procede del topónimo latino Trifinum, que servía para designar a una comarca situada en un territorio en el que confluían tren confines de tribus, con las que existía un convenium con la administración romana y que, en este caso, se correspondían con los várdulos, caristios y autrigones. Sin embargo, no todos están de acuerdo con esta procedencia, ya que su toponimia es también polémica ${ }^{2}$. Pero esto carece de relevancia para la presente investigación. Ahora bien, en opinión del Profesor Belda, toda evocación a las consultas populares de identidad que se relacionen con el País Vasco son especialmente sensibles para los medios de comunicación ${ }^{3}$. Y es aquí, en las reivindicaciones segregadoras del enclave, donde nuestra investigación se va a centrar.

Por una parte, la pertenencia del Enclave de Treviño a Burgos encuentra su justificación en la Historia. Así, Fernán González, conde de Castilla y señor de Álava otorgó, en el año 1025, al Monasterio de San Millán, el derecho a recaudar contribuciones sobre varios pueblos de Álava, entre los que se encontraba Treviño. Posteriormente, en 1366, Enrique II otorga a Don Pedro Manrique, adelantado mayor de Castilla, la villa de Treviño con sus aldeas ${ }^{4}$ y, en 1591, Treviño se adscribe a la provincia de Burgos por decisión de sus habitantes, desobedeciendo el mandato regio al respecto de no integrarse en la «Hermandad de Álava» ${ }^{5}$.

No obstante, la Historia también ofrece argumentos que justifican la reivindicación secesionista de Treviño. Así, su primer intento de reivindicar su pertenencia a Álava data de 1646 y, desde entonces, continúan intentándolo sin éxito, lo que ha convertido el problema de Treviño, según Arrando Aldasolo, en «un contencioso medieval que continúa sin resolverse en el siglo XXI» ${ }^{6}$. Poste-

2 Cfr., Martínez Gorriarán, C., «Del Parlamento Vasco, sobre alteración de los límites provinciales, consistente en la segregación de los municipios del Condado de Treviño y la Puebla de Arganzón de la provincia de Burgos y su incorporación al territorio histórico de Araba/Álava (Orgánica). Número de Expediente 125/000014»Diario de Sesiones del Congreso de los Diputados. Pleno y Diputación, Año 2014, X Legislatura, núm. 240, Sesión Plenaria núm. 225, celebrada el martes 18 de Noviembre de 2014, p. 13 Esta postura no es compartida por EsteBAN BRAVO, A., quien considera que la toponimia es vasca, cfr., «Del Parlamento vasco...», p. 9.

3 Cfr., Belda Pérez-Pedrero, E., «Condado de Treviño: La STC 99/86, de 11 de Julio, doce años después», La Justicia constitucional en el Estado democrático, Cortes de Castilla-La Mancha, Tirant lo Blanch, Valencia, 2000, p. 225.

4 Cfr., Tudanca Fernández, L., «Del Parlamento Vasco...», p. 15.

5 Cfr., Posición sostenida por la defensa del Parlamento de Castilla y León. STC 99/1986, de 11 de julio de 1986. Antecedente de Hecho nº 12.

6 Arrando Aldasolo, B., «Del Parlamento Vasco...», cit., p. 5. 
riormente, con el anteproyecto liberal de la división provincial, Javier de Burgos incluyó a Treviño dentro de Álava, pero en 1832 el enclave decidió abandonarla para mantenerse en tierras de señorío y evitar, así, formar parte de las tierras de realengo ${ }^{7}$. Además, desde 1919, los vecinos de Treviño han realizado numerosos intentos incorporativistas a Álava, pero todos fueron frustrados. Sin embargo, desde el 15 de febrero de 1951, en el terreno eclesiástico, Treviño forma parte de Álava. Por tanto, partiendo de este punto de vista, se entiende que Treviño es un residuo feudal ${ }^{8}$ llegando, incluso, a relacionarse el mantenimiento de esa situación con el derecho de pernada medieval ${ }^{9}$, en el que parece gobernarse más sobre súbditos que sobre ciudadanos, al mantener anacronismos medievales ${ }^{10}$. Así, los valedores de estas posturas defienden que Treviño pertenece a Burgos por derecho pero, de hecho, pertenece a Álava, lo cual se puede constatar jurídicamente en las amplias mayorías por las que, repetidas veces, ambos municipios solicitan su agregación al País Vasco ${ }^{11}$.

Así, cada vez que se alude a la Historia para legitimar la segregación de Treviño o su mantenimiento en Burgos ${ }^{12}$, ésta parece adquirir un cariz distinto según la posición política defendida, y es que, en palabras de Cicerón, «las leyes que se observan en la narración histórica se orientan a la verdad y en la poesía [las leyes que se usan] se orientan a embellecer las $\operatorname{cosas}^{13}$ ». Por ello, por un lado, cuando se quiere justificar la pertenencia histórica de Treviño a Burgos, se cae en el error de considerar que las decisiones tomadas por los representantes medievales de la época encuentran un equivalente democrático en las decisiones tomadas por los representantes políticos actuales ${ }^{14}$. De este modo, si tenemos en cuenta que los representantes medievales no representaban, efectivamente, a los

\footnotetext{
7 Cfr., Esteban Bravo, A. «Del Parlamento Vasco...», p. 10

${ }^{8}$ Cfr., Posición sostenida por los recurrentes vascos. STC 99/1986. Antecedente de Hecho $\mathrm{n}^{\circ} .6$.

9 Cfr., Arrando Aldasolo, B. «Del Parlamento Vasco...», p. 6.

10 Cfr., Páramo I Ponsetí, C., «Del Parlamento Vasco...», cit., p. 14.

11 Cfr., Urbina Fernández, I., Prieto San Vicente, T., Arrando Aldasolo, B., y Aguirre López, M., «Del Parlamento vasco...», pp. 5-9.

12 Criticando la remisión a historias medievales como argumentos políticos, cfr., MARTÍNEZ Gorriarán. C., «Del Parlamento Vasco...», p. 11.

13 Cicerón, M. T., Las Leyes, Traducción, introducción y notas por Álvaro D’ Ors, Instituto de estudios políticos, 1970, cit., p. 53.

14 Una crítica equivalente para otro asunto similar, Cfr., Ruipérez Alamillo, J., «La Constitución y su estudio. Un episodio en la forja del Derecho Constitucional europeo: Método jurídico y régimen político en la llamada Teoría Constitucional de Weimar», en C. León Bastos y V. A. Wong Meraz (coords.) y otros, Teoría de la Constitución. Estudios jurídicos en homenaje al Dr. Jorge Carpizo en Madrid, México, 2010, p. 790-793 y 850-851.
} 
intereses de sus ciudadanos, sino a los de su señor, comprobamos con facilidad el absurdo de sostener que los intereses de sus vecinos estaban asegurados, pues equivaldría a hablar de democracias medievales, y que su voluntad se correspondía con la de su Señor. Ocioso debería ser, por tanto, poner de manifiesto que, si así fuese, los treviñeses preferirían reducir sus contribuciones al Monasterio antes que resolver problemas administrativos ${ }^{15}$. Por otra parte, tampoco es correcto hablar de adscripciones territoriales en época medieval cuando se afirma que, en una fecha determinada, Treviño comenzó a formar parte de Burgos, pues esas vinculaciones eran personales, es decir, la tierra era propiedad de un Señor, pero éste podía alterar las anexiones de los territorios en la sucesión, ya que el territorio del Estado no dejaba de ser un fundo medieval. De esta forma, no puede hablarse en esa época de un concepto preciso de circunscripciones territoriales, si bien es cierto que, con la división de Florideblanca, a finales del siglo XVIII, se crean 31 Intendencias en toda España, con la finalidad de crear una administración estable, lo cual supuso, en realidad, la consolidación de la irracionalidad y obsolescencia administrativa del Antiguo Régimen ${ }^{16 .}$

Lo mismo ocurre cuando la Historia sirve de instrumento legitimador para las pretensiones secesionistas treviñesas. Así, García-Tizón López ${ }^{17}$ sostiene que no es posible defender, por un lado, los derechos históricos forales del País Vasco, de origen feudal y faltos de racionalidad administrativa, y al mismo tiempo, tildar de anacrónicos y feudales los derechos históricos en los que se basa Castilla y León para defender sus intereses de integridad territorial, a través de la defensa de la racionalidad administrativa y la eficiencia, pues ello supone una clara incoherencia política que deslegitima, con sus argumentos, las propias pretensiones nacionalistas.

15 Así, según el Profesor P. De Vega, la representación medieval equivalía a un mandato, en la medida en que el representante representaba, a través de la concesio o la traslatio, al representado, pero no al Pueblo en su conjunto. Representaba a su señor, a un municipio o corporación y estaba limitado por los límites conferidos dicho mandato. cfr., DE VEGA García, P., «La crisis de la representación política en la democracia de partidos», Tendencias contemporáneas del Derecho electoral en el mundo. Memoria del II Congreso internacional de Derecho electoral, UNAM, México, 1993, pp. 181-183. Sin embargo, en el caso de municipios, tampoco sus representantes representaban a los vecinos del lugar, sino a aquellos con poder suficiente para influir en las decisiones corporativas (gremios, cofradías...). También, del mismo autor, «Significación constitucional de la representación política», REP (Nueva Época), número 44, Marzo-abril, 1985, pp. 25-26.

16 Cfr., González Mariñas, P., Las Diputaciones provinciales en Galicia: Del Antiguo Régimen al constitucionalismo, Diputación provincial de La Coruña, Publicaciones: Escuela gráfica e impr. Provincial, Colegio Calvo Sotelo, A Coruña, 1978, pp. 28-31.

17 Cfr., García-Tizón López, A. «Del Parlamento Vasco...», p. 17. 
Posteriormente, ya en el siglo xxi, en 1940, plena época franquista, el gobierno permitió expresar la opinión de Treviño sobre la incorporación a la provincia alavesa a los cabezas de familia de ambos municipios, resultando una votación favorable del $75 \%$. Sin embargo, el gobierno franquista no hizo nada y Treviño continuó en la misma situación que antes ${ }^{18}$. Más adelante, el Condado de Treviño, el 26 de enero de 1980, y La Puebla de Arganzón, el 17 de octubre de ese mismo año, solicitaron la inclusión de sus municipios en el País Vasco a través del artículo 8 de su Estatuto ${ }^{19}$. A continuación, los respectivos ayuntamientos acordaron dar audiencia a la Comunidad (o ente preautonómico) y a la Diputación provincial a la que pertenecen. Así, al no existir procedimiento, lo tramitaron a través del art. 91 de la Ley del Procedimiento Administrativo, concediendo 15 días al Consejo Regional de Castilla y León y a la Diputación provincial de Burgos para presentar alegaciones relativas a la incorporación. Sin embargo, el presidente de la Diputación de Burgos rechazó el trámite por, según su parecer, no existir procedimiento legal al respecto, en Decretos de 24 de noviembre y 17 de diciembre de ese mismo año. No obstante, a pesar de la negativa, los municipios continuaron dicho procedimiento solicitando el referéndum ya que, según el mismo, el informe no era obligatorio. Así las cosas, el contencioso surgió cuando se aprobó el Estatuto de Castilla y León el 25 de febrero de 1983, al establecer un procedimiento para la segregación de Treviño que el Parlamento vasco consideró una vulneración de su competencia territorial, por lo que se recurrió dicho Estatuto ante el Tribunal Constitucional, y en la STC 99/1986 se rechazaron sus pretensiones. No obstante, el procedimiento establecido por el Estatuto de Castilla y León ha servido como un bloqueo procedimental a las reivindicaciones del enclave. De esta forma, en época democrática, se pidió, frustradamente, la segregación en 1991, $1995,1997,2005$ y $2013^{20}$.

Así, en 1995, se aprobó un texto similar para la alteración provincial por el cual Gátava pasaba a formar parte de Valencia ${ }^{21}$ y, en ese mismo año se creó, en la Comisión General de las Comunidades Autónomas del Senado, una ponencia sobre los enclaves territoriales en el que se aprobó, por unanimidad, constituir una comisión integrada por representantes del Gobierno vasco y de la Junta de Castilla y León, para resolver el problema de Treviño, de acuerdo con los procedimientos establecidos en ambos estatutos ${ }^{22}$, lo cual es conforme a la STC

\footnotetext{
18 Cfr., Esteban Bravo, A. «Del Parlamento Vasco...», p. 10.

19 Cfr., STC 99/1986. Antecedente 3 a) y b.

${ }^{20}$ Cfr. Esteban Bravo, A. «Del Parlamento Vasco...», p. 10.

21 Cfr., Sixto Iglesias, R. «Del Parlamento Vasco...», p. 13.

22 Cfr., Tudanca Fernández, L. «Del Parlamento Vasco...», pp. 15-16.
} 
99/1986. Sin embargo, el 5 de abril de 1998, los municipios del enclave burgalés realizaban un referéndum para manifestar su opinión sobre su pertenencia al País Vasco o a Castilla y León, votada la primera opción, favorablemente, por sus vecinos $^{23}$ pero, al haber sido convocada sin autorización, no produjo efectos legales $^{24}$. Es menester destacar, curiosamente, que este referéndum fue promovido por un alcalde del Partido Popular. El entonces Ministro de Administraciones Públicas, Mariano Rajoy, dijo en un primer momento que el referéndum no se haría, después tomo posiciones más tolerantes afirmando que no lo impediría y finalmente que lo recurriría a los Tribunales. Sin embargo, el referéndum se realizó igualmente y Rajoy dijo que, como eso era algo ajeno al gobierno, la solución correspondía a un consenso entre ambas Comunidades Autónomas ${ }^{25}$, lo cual constituye un antecedente mimético en su estrategia política respecto a Cataluña. Con posterioridad, el 8 de marzo del 2014, el Condado de Treviño y la Puebla de Arganzón acordaron, una vez más, la incorporación a la provincia de Álava. Así, el 6 de febrero de ese mismo año, el Parlamento vasco aprobó, por mayoría absoluta y sin ningún voto en contra, la presentación de una iniciativa legislativa sobre la alteración de los límites provinciales, consistente en la segregación de los mentados municipios de la provincia de Burgos y su incorporación de la provincia de Álava ${ }^{26}$. No obstante, es preciso aclarar que la iniciativa de la propuesta de Ley en realidad pertenece a los ayuntamientos de Treviño, a los cuales el parlamento vasco eleva su petición para remitirla con posterioridad al Parlamento de la Nación ${ }^{27}$.

Actualmente, la mayor parte de los vecinos del Enclave de Treviño hacen su vida y obtienen, o buscan obtener, sus servicios sociales en Vitoria. Así, el $60 \%$ de los niños de Treviño están escolarizados en Álava y dos de cada tres consultas sanitarias se hacen en la Comunidad Autónoma vasca ${ }^{28}$. Ello supone una administración ineficiente y absurda de los servicios públicos ${ }^{29}$, lo cual se puso de manifiesto cuando, en verano del 2013, murió una niña treviñesa por

23 Cfr., Arrando Aldasolo, B. «Del Parlamento Vasco...», p. 6.

24 Así, en opinión del Profesor E. Belda, la consulta de Treviño de 1998 fue una acción de presión de esos municipios, con la complicidad del gobierno vasco y la ignorancia del parlamento de Castilla y León, porque lo califica de un pseudoreferéndum. Cfr., Belda PÉrez-Pedrero, E., «Condado de Treviño...», p. 204 y 211.

${ }^{25}$ Cfr., Tudanca Fernández, L. «Del Parlamento Vasco...», pp. 15-16.

26 Cfr., Aguirre López, M. «Del Parlamento Vasco...», p. 5.

27 Cfr., Esteban Bravo, A. «Del Parlamento Vasco...», p. 9.

28 Cfr., Aguirre López, M. y Esteban Bravo, A. «Del Parlamento Vasco...», pp. 5 y 9.

29 Cfr., Urbina Fernández, I., Esteban Bravo, A. y Martínez Gorriarán, C. «Del Parlamento Vasco...», pp. 9-13. 
la indefinición del reparto competencial ${ }^{30}$. En realidad, existe un consenso mayoritario sobre la evidente relación económica y social de Treviño con Vitoria $^{31} \mathrm{y}$, precisamente, con la intención de arrojar un ápice de luz que permita obtener una solución para esta situación, se realiza esta investigación, pues, como sostiene Rousseau, «el amor al bienestar es el único móvil de las acciones humanas ${ }^{32} »$.

\section{PLANTEAMIENTO DE LA PROBLEMÁTICA CONSTITUCIONAL EN ATENCIÓN AL CASO CONCRETO}

Por tanto, de todo lo expuesto, no cabe dudar de que los intentos de Treviño por integrarse en la provincia de Álava no son exclusivos del actual periodo democrático, sino que se remontan mucho tiempo atrás. Sin embargo, lo que a nosotros nos interesa es la conformidad de las propuestas secesionistas del enclave con la vigente Constitución y con Estatutos de Autonomía, por lo que nos centraremos sólo en aquellas realizadas una vez aprobada nuestra vigente Norma Fundamental. Así, el conflicto surgido entre el Estatuto del País Vasco y el Estatuto de Castilla y León, con relación a la competencia territorial sobre el Enclave de Treviño, es lo que va a dar lugar a la STC 99/1986 y que supondrá un punto de inflexión en las reivindicaciones secesionistas treviñesas. De esta forma, aprobados los acuerdos de sendos municipios para la agregación del enclave en la Diputación vasca, siguiendo los trámites establecidos en la Ley de Procedimiento Administrativo de 1958, la cual está parcialmente derogada por la actual Ley 30/92 de Régimen Jurídico de las Administraciones Públicas, acordaron dar audiencia al Consejo Regional de Castilla y León y a la Diputación provincial de Burgos, produciéndose un silencio administrativo por parte de la primera, aunque el presidente de la segunda se manifestó afirmando la inexistencia de un procedimiento legal para ello ${ }^{33}$. Sin embargo, en virtud de dicho

30 Cfr., Martínez Gorriarán, C., «Del Parlamento Vasco...», p. 12.

31 Cfr., Belda Pérez-Pedrero, E., «Condado de Treviño...», p. 204 y las posiciones de Aguirre López, M. y Urbina Fernández, I. Cfr., «Del Parlamento vasco...», pp 5 y 8.

32 Rousseau, J. J., Discurso sobre el origen y los fundamentos de la desigualdad entre los hombres y otros escritos, (1753), Editorial Técnos, Madrid, 1987, cit., p. 164.

33 Esta decisión es duramente criticada por el Profesor A. Sánchez Blanco, quien considera que no se puede impedir un procedimiento porque no esté regulado, sino que la Administración tiene que responder en todo caso. Así, en caso de ausencia de informes, debería regir el silencio administrativo favorable para quien inicia el procedimiento, y en el caso concreto del informe, éste no ha de vincular a las Cortes Generales. Cfr., SÁnchez Blanco, A, «Ajustes territoriales en las Comunidades Autónomas. Derechos institucionales y Derechos de las Comunidades sociales. La 
procedimiento, como los informes no son vinculantes, los municipios continuaron los trámites y remitieron los acuerdos al Gobierno vasco para iniciar el procedimiento establecido en el artículo 8 su Estatuto y que, una vez aprobados, se convocase un referéndum en el que los vecinos pudieran decidir su identidad provincial.

Así, el mencionado precepto requiere, en primer lugar, para la incorporación de territorios o municipios que estuvieran enclavados en su totalidad dentro del territorio autonómico vasco, el acuerdo por mayoría simple de los municipios que decidan integrarse en la Comunidad Autónoma y, en segundo lugar, se establece que «se oiga» a la Comunidad o a la provincia a la que pertenezcan (art. 8.a). De ello se deduce que, al establecer que sean oídas ambas corporaciones, la resolución adoptada por las mismas no impide continuar el proceso, ya que es una audiencia facultativa y, además, se puede optar entre dar audiencia a una u otra, siendo innecesarias ambas resoluciones. A continuación, el acuerdo debe ser aprobado en referéndum por una mayoría de votos válidamente emitidos (art. 8.b), por lo que las abstenciones, votos en blanco o nulos no penalizan la votación referendaria, y solo es necesario, para la incorporación, que de los votos emitidos, la mayoría sean afirmativos. Sin embargo, ese referéndum, para que sea válido, debe ser autorizado por el Gobierno Nacional. Además, el acuerdo de incorporación debe ser aprobado por el Parlamento vasco y, finalmente, por las Cortes Generales, mediante Ley Orgánica, de acuerdo con el art. 141.1 de la vigente Constitución española.

No obstante, a pesar de las negociaciones y procedimientos administrativos realizados por el Gobierno vasco con las diferentes administraciones y con el Presidente del Gobierno de la Nación, no se logró la autorización de la celebración del referéndum solicitado por el enclave ${ }^{34}$. Así, se suspendió el procedimiento de secesión de Treviño y el 25 de febrero de1983 se aprobó, mediante Ley Orgánica 4/1983, el Estatuto de Castilla y León, en el cual se establece, en su Disposición Transitoria Séptima, el procedimiento de segregación de territorios de dicha comunidad, lo que impide que se reanude la secesión por el procedimiento vasco. De esta forma, ya iniciado el proceso de Treviño conforme a las disposiciones vascas, se aprueba un nuevo procedimiento para la segregación de territorios castellano-leoneses, lo cual dará lugar al conflicto ${ }^{35}$. Así, el 3 de junio de 1983, el Gobierno vasco formuló recurso de inconstitucionalidad

sentencia del Tribunal Constitucional 99/1986 relativa al condado de Treviño», RVAP., $\mathrm{n}^{\circ}$ 16, 1986, pp. 135-164.

${ }_{34}$ Cfr., Posición sostenida por los recurrentes vascos. STC 99/1986. Antecedente de Hecho no. 3.e.

35 Cfr., Sánchez Blanco, A, «Ajustes territoriales...», pp. 133-134. 
contra los apartados a) y b) de la Disposición Transitoria Séptima del Estatuto de Castilla y León, considerando que, a diferencia del presidente de la Diputación burgalesa, sí existe un procedimiento legal para realizar el proceso, esto es, a través de la Ley del Procedimiento Administrativo ${ }^{36}$. Por tanto, la Disposición Transitoria Séptima del Estatuto de Castilla y León, a diferencia del art. 8 del Estatuto vasco, exige que el acuerdo de separación sea adoptado por las dos terceras partes del número de hecho y, en todo caso, mayoría absoluta de los miembros de dichas corporaciones. Además, es necesario un informe favorable de la provincia y de la Comunidad Autónoma afectadas, a la vista de las mayores vinculaciones históricas, sociales, culturales y económicas con la Comunidad Autónoma a la que se solicite la incorporación. También es preciso un referéndum en el que se exige, al igual que en el Estatuto vasco, mayoría de los votos válidamente emitidos y aprobación por las Cortes Generales mediante Ley Orgánica.

De ello se extraen una serie de consecuencias. Así, en primer lugar, con esta disposición, supuestamente, el enclave ve seriamente agravado el procedimiento para la segregación ${ }^{37}$, pues ya no se exige mayoría simple para la adopción de los acuerdos de secesión, sino mayoría de dos tercios del número de hecho o mayoría absoluta. Además, no basta con oír solo a una las corporaciones afectadas, sino que es preciso el informe favorable tanto de la Diputación burgalesa como de la Comunidad Autónoma de Castilla y León siendo, de este modo, una audiencia preceptiva, por lo que su omisión o informe desfavorable supone la parálisis del procedimiento, sustituyéndose, así, la aprobación de un parlamento autonómico por los informes de equipos técnicos. Por otra parte, si tenemos en cuenta el número de concejales de los municipios objeto de la presente investigación, esa mayoría se agrava todavía más, por lo que la ausencia de uno de los concejales y la oposición de otro, o la abstención de ambos, impiden la adopción de dichos $\operatorname{acuerdos}^{38}$, equiparándose esa mayoría a la cuasiunanimidad. No obstante, a pesar de esas gravosas mayorías exigidas, dichos municipios adoptaron sendas resoluciones. Por otra parte, aunque irrelevante desde el punto de vista práctico, coincidimos con el Profesor Sánchez Blanco en que es criticable, desde el punto

36 Cfr., Posición sostenida por los recurrentes vascos. STC 99/1986. Antecedente de Hecho $n^{\circ} 3$.

37 Según el Profesor A. Sánchez Blanco, esta Disposición nace como una petición de la provincia de Burgos a cambio de su incorporación en la Comunidad Autónoma castellano-leonesa, exigiendo medios que asegurasen la permanencia de Treviño en su provincia. Considera además que el procedimiento estatutario castellano-leonés es asistemático y confuso, mientras que el procedimiento vasco es claro. Cfr., SÁNCHEz BlanCO, A, «Ajustes territoriales...», pp. 138-142.

38 Cfr., Belda PÉrez-Pedrero, E., «Condado de Treviño...», p. 222. 
de vista de la técnica jurídica, que el procedimiento de segregación de municipios se incluyese en una disposición rubricada como «Incorporación de provincias limítrofes» ${ }^{39}$.

Así las cosas, en el mencionado recurso de inconstitucionalidad, los recurrentes vascos ${ }^{40}$ van a defender que debe ser el Gobierno Nacional el que debe autorizar el referéndum por el que se decida el cambio territorial. Además, consideran que la Disposición Transitoria Séptima del Estatuto de Castilla y León y el art. 8 del Estatuto vasco recaen sobre un mismo objeto, la segregación de Treviño, por lo que se está reformando este último Estatuto sin seguir el procedimiento establecido, es decir, por reforma estatutaria o constitucional. Así, toda contradicción material que no se realizase por las vías legalmente establecidas, deberá ser considerada inconstitucional, de acuerdo con la STC de 12 de noviembre de 1981. Por un lado, ven que la aprobación de esta disposición por las Cortes Generales es una actuación arbitraria, ya que se le está permitiendo a los castellano-leoneses exigir un informe favorable que no se les permitió exigir a los vascos en su Estatuto de Autonomía, pues ambos Estatutos fueron aprobados por el Parlamento Nacional y no unilateralmente y, por otro lado, la Comunidad Autónoma de Castilla y León es la única en cuyo Estatuto de Autonomía se establecen procedimientos de segregación, por lo que se está atentando contra el principio de igualdad, al exigírseles requisitos a los vecinos de Treviño que no se les exigen al resto de ciudadanos españoles ${ }^{41}$. Sostienen, además, que el procedimiento vasco es completo y no puede desdoblarse en los procesos sucesivos de segregación y agregación, contando el art. 8 de su Estatuto con procedimientos mucho más democráticos que el castellano-leonés, al primar la voluntad de la población y de sus ayuntamientos, mientras que el segundo prima la Comunidad Autónoma y la provincia sobre la voluntad de los vecinos ${ }^{42}$. Por otra parte, la Disposición Transitoria Séptima castellano-leonesa deja sin contenido, según los recurrentes, al precepto vasco, correspondiéndole a su Estatuto el único trámite de aprobar la agregación por su parlamento autonómico. Finalmente, alegan que la disposición impugnada supone un derecho de veto ya que permite,

39 El Profesor A. Sánchez Blanco, sostiene que tanto la Diputación de Burgos como la Comunidad Autónoma de Castilla y León tienen medios suficientes para elaborar el informe, pero no lo hacen porque lo usan para vetar la voluntad treviñesa. Cfr., SánCHEZ BlanCo, A, «Ajustes territoriales...», pp. 140-150.

${ }^{40}$ El Profesor E. Belda, considera que el Tribunal Constitucional adopta esta decisión para no alterar los Estatutos de Autonomía. Cfr., Belda Pérez-Pedrero, E., «Condado de Treviño...», p. 210.

${ }^{41}$ Cfr., STC 99/1986. Antecedentes de Hecho n 1, 3, 4, 7 y 8.

42 Cfr., SÁnChez Blanco, A, «Ajustes territoriales...», pp. 138. 
a ambas corporaciones, un margen de discrecionalidad tal que se transforma en auténtica arbitrariedad $^{43}$. Por otra parte, el Magistrado don Jesús Leguina Villa, en el voto particular de la comentada sentencia constitucional, coincide plenamente con esta posición y critica la resolución de la sentencia ${ }^{44}$, comenzando por afirmar que la metodología defendida por la mayoría del Tribunal lo que en realidad hace es cotejar los Estatutos en lugar de analizar su adaptación a la norma constitucional ${ }^{45}$.

Por su parte, el Abogado del Estado considera que Treviño queda fuera del ámbito territorial regulado por el Estatuto vasco, ya que, como parte de Burgos, accedió a la autonomía cuando se constituyó la Comunidad Autónoma de Castilla y León. Defiende, también, que al País Vasco le corresponde, dentro de su ámbito normativo, regular las cuestiones de agregación mientras que a Castilla y León le corresponde regular el procedimiento de segregación, por lo que no se está restringiendo la competencia vasca ni modificando sus mayorías exigidas en el Estatuto vasco, pues desde un inicio carecía de dicha competencia, por lo que los trámites realizados antes de aprobarse el Estatuto de Castilla y León solo son válidos en el País Vasco. En una línea similar, la defensa castellano-leonesa, va a sostener que el territorio es un elemento constitutivo de las Comunidades Autónomas, basándose en el art. 147 de la Constitución española, por lo que es competencia estatutaria regular los requisitos de segregación ${ }^{46}$. También, al igual que el Abogado del Estado, defiende la necesidad conjunta de los informes de la provincia y la Comunidad Autónoma por la relevancia que supone la alteración territorial para dichas corporaciones, por lo que ambas han de poder participar en la decisión y, además, la misma no solo no es arbitraria, ya que siempre es controlable por los Tribunales Contencioso-Administrativos sino que, además, no existe ningún precepto constitucional que obligue a las Comunidades Autónomas a tener un papel meramente consultivo en esa decisión. Así, no se trata de un derecho de autodeterminación de Treviño, sino de conectar la voluntad de los municipios del enclave con los territorios afectados, por lo que

43 Íbidem, pp. 138-147.

44 Reforzando esta crítica, el Profesor A. Sánchez Blanco, además de coincidir plenamente con ella, defendiendo que el procedimiento a seguir era el art. 8 del Estatuto vasco, sostiene que la sentencia antepone las condiciones jurídico-formales a los problemas del Condado de Treviño. Íbiden, pp. 135-159.

${ }^{45}$ Defendiendo esta opinión, por considerar que esta interpretación puede plantear problemas al bloque de constitucionalidad, cfr., Belda PÉrez-Pedrero, E., «Condado de Treviño...», p. 204.

46 Cfr., STC 99/1986. Antecedente de Hecho n ${ }^{\text {os }} 11$ y 12.a. 
todos deben participar en el acuerdo ${ }^{47}$. Por otra parte, la defensa castellanoleonesa sostiene que es necesaria la reforma estatutaria para la agregación territorial de Treviño a Álava ${ }^{48}$ y, finalmente, el Abogado del Estado propone una interpretación según la cual establece que, en caso de conflicto, debe ser el Estado el que deba solucionarlo en última instancia para impedir el veto a través de los informes favorables, lo cual considera más aceptable que hacer depender una decisión de las Comunidades Autónomas de la resolución de los Tribunales Contencioso-Administrativo ${ }^{49}$. Dicha interpretación no fue adoptada por el Tribunal Constitucional pero si lo será por las posiciones nacionalistas en el debate parlamentario del 2014.

Finalmente, por lo que se refiere a la interpretación del Tribunal Constitucional, admite parcialmente todas las alegaciones esgrimidas por la defensa castellano-leonesa y por el Abogado del Estado. Así, para proceder a realizar dicha valoración, comenzará analizando si los Estatutos de Autonomía respetan la Constitución, evitando proceder a un simple cotejo de los mismos. De este modo, se busca delimitar el ámbito territorial sobre el cual pueda regular cada Comunidad Autónoma. Por tanto, concluye el Tribunal Constitucional, «el único parámetro para enjuiciar la validez constitucional de una disposición incluida en un Estatuto es la propia Constitución ${ }^{50} \gg$ Así, admite la separación entre la fase de segregación, cuya regulación corresponde a Castilla y León en su Estatuto de Autonomía ${ }^{51}$, y la fase de agregación, cuya regulación corresponde al Estatuto de Autonomía del País Vasco, por lo que no existe identidad de objetos $^{52}$ en la regulación de ambos preceptos, ya que cada Comunidad Autónoma los puede regular con total libertad, con el único límite de que dicha alteración deberá ser aprobada por Ley Orgánica. Por tanto, ambos preceptos recogen el contenido del art. 147.2.b de la Constitución española, es decir, las previsiones sobre la alteración territorial (segregación y agregación), aunque

${ }^{47}$ Cfr., STC 99/1986. Antecedentes de Hecho n ${ }^{\text {os }} 11 . b$ y 12.a.

48 Cfr., STC 99/1986. Antecedente de Hecho n 12.a.

49 Cfr., STC 99/1986. Antecedente de Hecho nº 11.b. Esta decisión es defendida por el Profesor A. Sánchez Blanco, Cfr., SÁnchez Blanco, A, «Ajustes territoriales...», pp. 145-146.

50 STC 99/1986, Fundamento Jurídico 4. cit.

51 Cfr., STC 99/1986. Fundamento Jurídico 5.

52 El Tribunal Constitucional sostiene, en un inicio, que los requisitos para la agregación y segregación son a la vez coincidentes en ambos Estatutos (solicitud por los ayuntamientos, celebración de referéndum, aprobación por Ley Orgánica...), pero a la vez contienen disparidades (diferencias de mayorías cualificadas para la aprobación del los acuerdos municipales de agregación/ segregación y en la intervención de la Comunidad Autónoma, que en el Estatuto de Autonomía País Vasco basta la mera audiencia de la misma y en el de Castilla y León es preciso el informe favorable de ambas corporaciones). Cfr., STC 99/1986. Fundamento Jurídico 2 y 3. 
ambos tengan un mismo resultado ${ }^{53}$. Así, sostiene, al tener que ser aprobada por las Cortes Generales, no es posible la arbitrariedad ni la discreccionalidad ${ }^{54}$. Por ello, según el Tribunal Constitucional, los Estatutos de Autonomía tienen límites normativos, a saber: los contenidos que afectan a una Comunidad Autónoma no pueden quedar fijados en los Estatutos de otra, pues ello limitaría su autonomía y se estarían regulando materias sin la participación de ese territorio, por lo que «el Estatuto de una Comunidad no puede regular de un modo «completo y acabado» la segregación y la correspondiente agregación de los enclaves ubicados en su territorio cuando éstos pertenecen al de otra Comunidad Autónoma ${ }^{55} »$. Además, el Tribunal, tampoco ve un inconveniente en la diversidad de procedimientos, pues la misma permite la pluralidad y un verdadero autogobierno. De esta forma, lo que está haciendo el Tribunal Constitucional es, siguiendo interpretaciones kelsenianas ${ }^{56}$, definir el territorio como la extensión geográfica en donde tiene su ámbito de vigencia un ordenamiento jurídico. Por último, en la misma línea que el Abogado del Estado y la defensa castellanoleonesa, defiende el informe favorable y considera que no se está modificando un Estatuto a través de otro posterior, sino que cada uno tiene competencia solo en su ámbito territorial ${ }^{57}$.

Cabe concluir, por tanto, que la decisión del Tribunal Constitucional es jurídicamente correcta. Así, coincidimos con la interpretación del Abogado del Estado cuando sostiene que Treviño está fuera de la delimitación territorial vasca, ya que al no haberse llevado a cabo la alteración provincial por el Parlamento Nacional, antes de la aprobación del Estatuto de Castilla y Léon, a través de Ley Orgánica, de acuerdo con el art. 141.1 de la Constitución española, Treviño formaba parte de Burgos en el momento de acceder a la autonomía, por lo que el Estatuto castellano-leonés también le es aplicable. Ello supone que es a la Diputación de Burgos a la que jurídicamente corresponde la defensa de los intereses de Treviño y no a ninguna Diputación vasca, aunque Álava asuma materialmente su defensa. Así, desde el punto de vista jurídico, por muy escasamen-

53 Cfr., STC 99/1986. Fundamento Jurídico 6 y 7.

54 Cfr., STC 99/1986. Fundamento Jurídico 9. Este argumento carece de sentido pues el Parlamento puede, al otorgar demasiada discrecionalidad a una administración, dar lugar a que la misma incurra en arbitrariedad.

55 Cfr., STC 99/1986. Fundamento Jurídico 6.

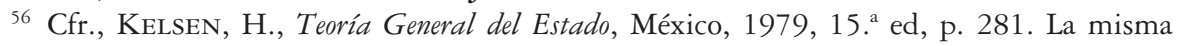
concepción del territorio es defendida por el Profesor J. Ruipérez. Cfr., Ruipérez Alamillo, J., Formación y determinación de las Comunidades Autónomas en el ordenamiento constitucional español, Técnos, segunda edición, Madrid, 1996, p. 101-103.

${ }_{57}$ Cfr. STC 99/1986., Fundamento Jurídico 9 y 10. 
te representado que estuviese Treviño en la Diputación burgalesa, lo cierto es que lo estaba, y mientras el Parlamento no aprobase la alteración territorial, éste debería acatar las decisiones provinciales al formar parte de la misma ${ }^{58}$, por lo que la resolución provincial de acceder a la autonomía también vinculaba al Enclave de Treviño 59 . Por otra parte, entendemos que el País Vasco es competente para regular en su Estatuto todo lo relativo a la agregación de Treviño y Castilla y León lo es para regular su segregación, ya que, como pone de manifiesto, con suma claridad, el Profesor Ruipérez, «Esto se debe a que cada uno está únicamente regulando la vertiente del derecho de autodeterminación que les incumbe, sin que pueda afirmarse que se produce una intromisión en la esfera de la otra Comunidad ${ }^{60}{ }$. Por ello, para llevar a cabo la segregación, deben primar las mayorías establecidas en el Estatuto de Castilla y León, no sólo porque con sus mayorías cualificadas se garantiza de manera más eficaz una verdadera voluntad corporativa de secesión, debiendo primar siempre la mayoría más garantista, sino que, además, la Comunidad Autónoma vasca carece de competencia para regular sobre esta materia. Por ello, el Estatuto vasco será válido, en relación con la secesión del enclave, en todo aquello que no contradiga al Estatuto castellano-leonés; en el resto de supuestos, para este caso concreto será inconstitucional. Así, la Disposición Transitoria Séptima del Estatuto de Castilla y León exige también que han de cumplirse los requisitos que establece el art. 8 del Estatuto vasco ${ }^{61}$. Sin embargo, esta interpretación, que entendemos correcta, puede plantear una serie de problemas.

Así, según el Profesor Belda, al considerar que ambos procedimientos recaen sobre un mismo objeto, se produce el solapamiento de ambas regulaciones en el que el Estatuto castellano-leonés puntualiza al vasco y, por tanto, caben dos posibilidades: o bien se considera que, una vez cumplidos los requisitos de iniciativa de las corporaciones, el informe favorable y referéndum del Estatuto castellano-leonés, se cumplen también los requisitos del Estatuto vasco, restando sólo la aprobación del Parlamento vasco y de las Cortes generales; o bien es necesario que se cumplan las mayorías absolutas municipales para la adopción del acuerdo de segregación, se emitan los informes favorables de la Diputación

58 Cfr., Belda Pérez-Pedrero, E., «Condado de Treviño...», pp. 223-225. Esto pone de manifiesto la incoherencia jurídica que supone que sea una Diputación ajena la que se encargue de representar los intereses una parte del territorio de otra.

59 En contra de esta opinión, por considerar que la Disposición castellano-leonesa contradice el Estatuto vasco y que de no haberse aprobado, debería haberse aplicado éste, cfr., BELDA PÉREZPedrero, E., «Condado de Treviño...», p. 206.

60 Ruipérez Alamillo, J., Formación y determinación..., cit., p. 132.

61 Íbidem, p. 132. 
de Burgos y la Comunidad Autónoma de Castilla y León, se celebre un referéndum para la segregación y se apruebe por las Cortes Generales mediante Ley Orgánica y, posteriormente, se adopten los acuerdos municipales de agregación mediante mayoría simple, se les vuelva a dar audiencia facultativa a los entes afectados, se celebre un referéndum para la agregación y, finalmente, se apruebe por el Parlamento vasco y por las Cortes Generales mediante Ley Orgánica.

En otro orden de consideraciones, también fueron denunciados algunas imperfecciones de la mencionada Disposición. Así, en primer lugar, la emisión de los informes no favorables o su ausencia ${ }^{62}$ podrían producir el bloqueo procedimental ${ }^{63}$ al basarse más en implicaciones políticas que jurídicas ya que, aunque el informe supone una valoración basada en conocimientos especializados, puede acabar haciéndolo en criterios personales no tan técnicos ${ }^{64}$, dando lugar a una posible arbitrariedad ${ }^{65}$. Además, en una de las enmiendas al Estatuto de Castilla y León se propuso substituir el término impreciso de «informes» por términos más precisos como «aprobación» ${ }^{66}$, donde es posible expresar claramente la opinión política, pero tales enmiendas fueron rechazadas. Otra eventual dificultad se refiere a las vinculaciones históricas, sociales, culturales y económicas con la Comunidad Autónoma a la que se solicite la incorporación, ya que los factores a valorar en el informe pueden entrar en conflicto entre sí ${ }^{67}$. Así, al igual que el Profesor Belda, consideramos que la opción de seguir un procedimiento único es la adecuada para evitar duplicidades ${ }^{68}$. Cabe concluir, por tanto, que es a Castilla y León a quien corresponde regular la segregación de Treviño y que, aunque es posible entrar a valorar las virtualidades y defectos políticos de la Disposición Transitoria Séptima, éste no es nuestro objeto de estudio.

${ }^{62}$ No obstante, la Ley 30/92 de Régimen Jurídico de las Administraciones Públicas incorpora en su art. 42 el deber de toda Administración de resolver mediante resolución expresa en todo procedimiento iniciado ante ella y, el art. 43.2, positiviza los efectos del silencio, al disponer que los interesados podrán entender estimadas por silencio administrativo sus solicitudes salvo que una norma con rango de Ley o de Derecho Comunitario establezca lo contrario. Como complemento, el art. 83 de la misma Ley 30/92 establece un plazo de diez días para la evacuación de informes, con apercibimiento de responsabilidad por la demora y pudiendo proseguir las actuaciones cualquiera que sea el carácter del informe solicitado.

${ }^{63}$ Cfr., Belda Pérez-Pedrero, E., «Condado de Treviño...», p. 213.

${ }^{64}$ Cfr., SÁnchez Blanco, A, «Ajustes territoriales...», pp. 138-147.

${ }^{65}$ Según el Profesor E. Belda, debió contarse con los municipios afectados al elaborar la mencionada disposición. Cfr., Belda Pérez-Pedrero, E., «Condado de Treviño...», p. 225.

${ }^{66}$ Cfr., Diario de Sesiones del Congreso de los Diputados, 1983, II Legislatura, num. 9. Sesión 26 de enero de 1983, pp. 313-315.

${ }^{67}$ Cfr., SÁnchez Blanco, A, «Ajustes territoriales...», p. 163.

${ }^{68}$ Cfr., Belda Pérez-Pedrero, E., «Condado de Treviño...», pp. 212-213 y 225. 


\section{PROPUESTAS Y RESOLUCIÓN PARLAMENTARIA}

Posteriormente, el 30 de noviembre del 2007 se aprueba la reforma del Estatuto de Autonomía de Castilla y León, mediante la Ley Orgánica 17/2007. Por lo que a nosotros interesa, el contenido de las Disposición Transitoria Séptima del derogado Estatuto pasa sin cambios, jurídicamente relevantes, a la Disposición Transitoria Tercera del nuevo ${ }^{69}$, corrigiendo, eso sí, su rúbrica, pasando a denominarse «Segregación de enclaves». No obstante, su debate parlamentario estuvo cargado de polémica. Así, frente a las propuestas que defendían que los informes no fuesen obligatorios, ya que podrían utilizarse para bloquear el procedimiento, D. Santiago-Suárez ${ }^{70}$, entre otros, se opuso a las mismas con la manifiesta finalidad de asegurar la integridad de Castilla y León ${ }^{71}$. Derivado de ello, el 6 de febrero del 2014, el Pleno del Parlamento vasco aprobó, por mayoría absoluta y sin ningún voto en contra, la presentación de una iniciativa legislativa sobre la alteración de los límites provinciales, consistente en la segregación de los municipios de Condado de Treviño y La Puebla de Arganzón de la provincia de Burgos y su incorporación al territorio histórico de Álava ante las Cortes Generales, admitida a trámite, debatida posteriormente en el Parlamento Nacional como propuesta de Ley Orgánica ${ }^{72}$ y rechazada por 28 votos a favor, 276 votos en contra y 19 abstenciones de 323 votos emitidos en total ${ }^{73}$. Así, Amaiur ${ }^{74}$ y Convergencia I Uniò ${ }^{75}$ votaron a favor la propuesta de resolución parlamentaria, UPyD se abstuvo y Izquierda Plural ${ }^{76}$, el grupo socialista y el $\mathrm{PP}^{77}$ votaron en contra. Pero tampoco es la primera vez que este tema es rechazado en las Cortes Generales ${ }^{78}$.

69 A. Esteban Bravo, considera que las nuevas mayorías están agravadas en la Disposición del vigente Estatuto de Autonomía de Castilla y León. Cfr., «Del Parlamento vasco...», p. 10.

70 Parlamentario castellano por Valladolid, representante del PP, consejero de Presidencia y portavoz de la Junta castellanoleonesa en esas fechas.

71 Posición sostenida por A. Esteban Bravo, el cuál defiende que tal decisión anula el art. 8 y excluye la voluntad de los Treviñeses. Sin embargo, aunque defendemos, como anteriormente se expuso, que aunque es cuestionable que los informes agravan el procedimiento, el art. 8 del Estatuto vasco sigue plenamente vigente. Cfr., Esteban Bravo, A., «Del Parlamento Vasco...», p. 10 .

72 Ibidem, p. 5.

73 Ibidem, p. 56.

${ }^{74}$ Ibidem, pp. 8, 11.

75 Ibidem, p. 14.

76 Ibidem, p. 13.

77 Ibidem, p. 16.

78 Cfr., Esteban Bravo, A., «Del Parlamento Vasco...», p. 9. 
Sin duda alguna, lo que más cabe destacar de este debate es la ausencia de su objeto. Así, Treviño es usado por los parlamentarios para introducir en sus discursos cualquier propuesta política, tangente al tema, defendida por su partido. Las pocas propuestas sobre Treviño son una reminiscencia a lo sostenido por los recurrentes vascos y castellano-leoneses en la STC 99/1986. Además, realizando unas prácticas parlamentarias desgraciadamente inusuales, posiblemente motivadas por los escasos intereses partidistas en juego, una de las críticas más habituales en el debate parlamentario es que un partido, en lugar de votar en bloque en todas y cada una de las Cámaras en las que se encuentra representado al mismo tiempo, haciendo gala de una férrea disciplina de partido, votase en función de los intereses de los ciudadanos a los que representa según la instancia política en la que se encuentre. Así, al parecer, que los parlamentarios vascos y castellano-leoneses defiendan los intereses de su comunidad y no los de su partido, y que los parlamentarios centrales, en lugar de representar los intereses de la provincia que los elija, representen al Pueblo español en su conjunto, es algo que repugna a muchos. Por tanto, no cabe hablar de una crisis o una ignorancia del principio de representatividad, sino de una esquizofrenia representativa-imperativa. Sin duda alguna, no se trata de un problema partidista sino de intereses territoriales ${ }^{79}$.

Así, por una parte, Urbina Fernández ${ }^{80}$, del grupo mixto, representante de Amaiur, reta a Alonso, vasco y miembro del PP, a abstenerse como hizo su partido en la Cámara de Vitoria o atreverse a realizar una incoherencia política y votar en contra. Martínez Gorriarán ${ }^{81}$, por su parte, acusa a los socialistas castellano-leoneses de que no hayan propuesto hasta ahora una ley autonómica para desagregar a Treviño para que luego el Parlamento Nacional pudiese decidir. Sin embargo, Alonso, aunque es vasco, se opone a la propuesta porque sostiene que incumple la Ley ${ }^{82}$. Por otra parte, García-Tizón López critica al PSOE porque su partido votó a favor de la secesión en Vitoria y en contra en la Cámara del Congreso. Así, es preciso destacar que el intercambio a todas estas críticas suponen una caótica esquizofrenia de virtud política representativa.

Por lo que se refiere a las propuestas tangentes al objeto de debate, Esteban $\mathrm{Bravo}^{83}$, por su parte, representante del PNV, criticará que aquellos que defienden la racionalidad y la eficacia de la Administración, en una clara alusión al PP, votarán en contra de llevarla a cabo al impedir la incorporación de Treviño

\footnotetext{
79 Cfr., Tudanca Fernández, L., «Del Parlamento Vasco...», pp. 16-17.

${ }^{80}$ Cfr., Esteban Bravo, A., «Del Parlamento Vasco...», p. 9.

81 Ibidem, p. 12.

82 Ibidem, pp. 16-17.

83 Ibidem, p. 9.
} 
y que el PSOE, defensor de que los ciudadanos están por encima de los anacronismos históricos, también votará en contra, acusando a ambos de rechazar la propuesta por incumplir los Estatutos, cuando no han sido observados muchas veces por ellos mismos. También Martínez Gorriarán aprovecha para criticar al modelo provincial, al que califica de anacrónico ${ }^{84}$, culpándolo de la situación de Treviño ${ }^{85}$. Pero sin duda alguna, el principal debate en el que se centraron todos los participantes fue en temas de unidad nacional. Así, muchos representantes

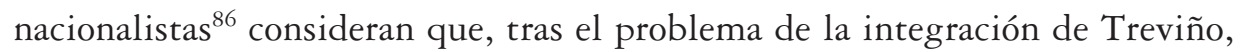
se esconde una defensa desesperada por la Unidad de España y que, tras la negativa a la integración, está el miedo a la ruptura del territorio nacional, parodiando el uso del enclave como campo de batalla, pues la Unidad de España, opinan, no se juega en un territorio de 2000 habitantes, llegando incluso a ver, $\operatorname{otros}^{87}$, en la propuesta de Treviño, la defensa por la autodeterminación ejerci-

${ }^{84}$ En defensa de la actualidad de las Diputaciones Provinciales, cfr., Cabanas Veiga, M., «Las Diputaciones Provinciales gallegas en la recesión económica actual y la crisis del principio de autonomía local», AFDUDC, $\mathrm{n}^{\circ}$ 18, 2004. Así, Carbonell Porras considera que «algo de bueno habrán aportado las provincias como divisiones del territorio nacional en general que, por lo menos, aconsejan ser cauteloso frente a quienes abiertamente y sin profundizar en el tema abogan por su supresión, y que este planteamiento de partida no es incompatible con la conveniencia de mejorar los aspectos más controvertidos o, incluso, de cuestionarnos si sería procedente eliminar su consideración como ente local básico previa la preceptiva reforma constitucional». CARBONELL Porras, E., «La división del territorio en provincias y su evolución», Sobre un bito jurídico, La Constitución de 1812. Reflexiones actuales, estados de la cuestión, debates historiográficos, Universidad de Jaén, Jaén, 2012, cit., pp. 538-539. En una línea similar, Salvador Crespo entiende que tampoco debería suprimirse la institución provincial al considerar que sobre la existencia de ésta, como parte del sistema institucional, no puede existir una reformulación permanente, ya que sería peligroso para la estabilidad del sistema democrático. Vid., SAlvador Crespo, M., «Las Diputaciones provinciales en la Constitución de Cádiz de 1812», Sobre un hito jurídico, La Constitución de 1812. Reflexiones actuales, estados de la cuestión, debates historiográficos, Universidad de Jaén, Jaén, 2012, pp. 555-556. Otros autores recalcan que con la desaparición de las Diputaciones Provinciales muchos municipios podrían quedar desprotegidos e, incluso, excluidos, ya que éstas cumplen una importante función social. Afirma, por tanto, que «el papel que desempeñan las Diputaciones para las provincias no se puede medir únicamente en términos económicos, sino que los sociales pueden ser aún más importantes. Cfr., Cano Rubio, M. D., «Cómo el liberalismo económico influye en la regulación socio-económica de un país: El papel de las Diputaciones provinciales», Sobre un hito jurídico, La Constitución de 1812. Reflexiones actuales, estados de la cuestión, debates historiográficos, Universidad de Jaén, Jaén, 2012, pp. 584 y 587, y MíGuez MaCHADO, L., «Galicia y la reforma de la Administración Local», Revista Xurídica da Universidade de Santiago de Compostela, $\mathrm{n}^{\circ}$ extra 1, noviembre, 2013, p. 326.

${ }^{85}$ Cfr., Martínez Gorriarán, C., «Del Parlamento vasco...», p. 12.

${ }^{86}$ Cfr., Esteban Bravo, A., «Del Parlamento vasco...», p. 10.

${ }^{87}$ Cfr., PÁramo I Ponsetí, C., «Del Parlamento vasco...», p. 15. 
tada a través de la separación de España para posterior anexión a Euskadi. Por otro lado, Tudanca Fernández ${ }^{88}$ critica que los parlamentarios vascos invitados (M. Aguirre López, T. Prieto San Vicente y B. Arrando Aldasolo) destacan más el elemento identitatario que los motivos funcionales y administrativos. Sin embargo, él mismo aborda la problemática de la Unidad de España al acusar a Esteban Bravo de que el fracaso del Pacto adoptado en el Senado ${ }^{89}$ para solucionar el problema de Treviño, en 1995, se debió a que el PNV iniciara una deriva independentista con el Pacto de Lizarra y que desembocó en el Plan Ibarretxe, poniendo, así, fin al consenso unánime alcanzado en el Senado. Por tanto, en el debate parlamentario se pone de manifiesto que tras el problema de Treviño lo que realmente se esconde es el debate secesionista vasco, recibiendo Treviño sus daños colaterales.

Y por lo que se refiere al escaso debate sobre Treviño, Esteban Bravo ${ }^{90}$ defendió, como en su momento lo hicieron los recurrentes vascos, que sólo el Estatuto castellano-leonés contiene una cláusula de segregación de enclaves, a lo que cabe responder lo dicho en su momento por el Tribunal Constitucional y sus contrincantes en el pleito, a saber: que de acuerdo con su competencia territorial, puede regular todas las alteraciones territoriales que sean de su competencia y que la pluralidad de regulaciones es lo que da verdadera virtualidad a la autonomía política. Así, casi 30 años después, las propuestas políticas y jurídicas a favor y en contra parecen no haber madurado. Por un lado, algunos parlamentarios defienden que la reivindicación de Treviño es conforme al ordenamiento jurídico y el principio de continuidad territorial ${ }^{91}$. Por otro lado, adoptando la solu-

${ }^{8}$ Cfr., Tudanca Fernández, L., «Del Parlamento Vasco...», pp. 15-16.

89 Esto no le resta legitimidad democrática a dichos acuerdos, ya que esta forma de adoptar decisiones se adapta a las nuevas necesidades del Estado y es propia del funcionamiento de los partidos políticos. Así, también, la Constitución fue debatida previamente antes de llevarse al Parlamento. Cfr., Ruipérez Alamillo, J., La Constitución del Estado de las Autonomías. Teoría constitucional y práctica política en el «federalising process» español, Ed. Biblioteca Nueva S. L., Madrid, 2003, p. 132.

90 Cfr., Esteban Bravo, A., «Del Parlamento Vasco...», p. 10.

91 Cfr., PÁramo I Ponsetí, C., «Del Parlamento Vasco...», pp. 14-15. Por otra parte, otros sostienen que la cercanía no se puede utilizar como argumento porque el art. 143 de la Constitución española no impone la continuidad territorial a la provincia y, además, hay poblaciones más cercanas a Álava como Logroño. Esta es la posición sostenida por García-Tizón López. Cfr., «Del Parlamento Vasco...», p. 17. Además, entendemos, la continuidad provincial exigida por la Constitución está garantizada, pues la provincia de Burgos limita con las restantes provincias castellano-leonesas, formando todas ellas un territorio compacto, pero no se exige que deba serlo así la totalidad del territorio provincial. Así, el art. 143 de la Constitución exige que las Comunidades Autónomas estén formadas por provincias limítrofes, formando todas ellas una unidad compacta, pero el Constituyente deja al legislador ordinario libertad para organizar el territorio provincial. 
ción interpretativa que el Abogado del Estado había propuesto en la STC 99/1986, los representantes nacionalistas van a defender que sea el Estado el que, unilateralmente, haga posible la alteración territorial provincial, debido al bloqueo que supone la Disposición Transitoria Tercera del Estatuto de Castilla y León ${ }^{92}$, pues desde el comienzo de la democracia se han intentado llevar a cabo todos los procedimientos legales previstos para realizar dichas alteraciones, pero siempre fracasan por el rechazo de la Diputación burgalesa y la Comunidad Autónoma castellano-leonesa ${ }^{93}$. Sin embargo, es absolutamente legítimo que un territorio defienda su interés territorial ${ }^{94}$. Así, en contra de esta opinión, otros parlamentarios defienden que el problema puede solucionarse por cauces jurídicos, ya que están en juego normas del bloque de constitucionalidad y, de hacerlo por vías legales, la propuesta legislativa obtendría una votación positiva ${ }^{95}$. Otros sostienen que hay que poner cauces que permitan levantar el bloqueo político al que está sometido Treviño y permitir el juego democrático ${ }^{96}$ a través del consenso ${ }^{97}$. Así, García-Tizón López ${ }^{98}$ expone que no es posible modificar un Estatuto de Autonomía a través de una Ley propuesta en el Parlamento, ya que ello no respetaría los cauces legales establecidos y, si se hiciese, sentaría precedentes muy dañinos. Además, sostiene que no reconocer la segregación de Treviño no les resta derechos a sus habitantes, ya que el Estatuto vasco no reconoce un plus de derechos, por lo que tendrán los mismos en Castilla y León que en el País Vasco.

Cabe señalar, además, que esta propuesta supone una clara mutación constitucional, ya que se busca dotar al art. 141 de la Constitución española de un

Por tanto, mientras que es necesario que el territorio autonómico sea limítrofe, nada dice la Constitución al respecto del territorio provincial.

92 Cfr., Aguierre López, M., Prieto San Vicente, T. y Esteban Bravo, A. También es sostenida por Urbina Fernández, I., pero aunque pone en cuestión la legalidad del procedimiento, dice que en cualquier caso es una decisión de las Cortes generales. «Del Parlamento Vasco...», pp. 5,7-9 y 11 .

93 Cfr., Arrando Aldasolo, B., Esteban Bravo, A. y Páramo I Ponsetí, C., «Del Parlamento Vasco...», pp. 6, 9, 10 y 15. R. Sixto Iglesias, defenderá que aunque las condiciones exigidas por la Disposición Transitoria Tercera del estatuto de Castilla y León son leoninas y supone un bloqueo por parte de la Diputación burgalesa, no se puede incumplir la Ley. Ibidem, pp. 13 y 18.

94 Cfr., Sixto Iglesias, R. y García-Tizón López, A., «Del Parlamento Vasco...», p. 13 y 15 .

95 Cfr., Martínez Gorriarán, C., Sixto Iglesias, R., Tudanca Fernández, L., y García-Tizón López, A., «Del Parlamento Vasco...», pp. 13, 15-16 y 18.

96 Cfr., Sixto iglesias, R., «Del Parlamento Vasco...», p. 13.

97 Cfr., Tudanca Fernández, L., «Del Parlamento Vasco...», pp. 16-17.

98 Ibidem, p. 18. 
significado distinto pero manteniendo su literalidad, pues si bien es cierto que el Estado posee la competencia para llevar a cabo las alteraciones territoriales, no puede cambiar unilateralmente las delimitaciones territoriales de las Comunidades Autónomas. De esta forma, la mutación está limitada por el respeto a la propia Constitución ${ }^{99}$, por lo que ponerla en marcha supondría un quebrantamiento de las normas del bloque de constitucionalidad, lo que se traduciría, en nuestra humilde opinión, siempre sometida a mejor criterio, en un falseamiento constitucional, otorgando a las normas constitucionales un sentido distinto del que realmente tienen ${ }^{100}$. Así, en palabras del Profesor Ruipérez, «lo que determina la constitucionalidad o inconstitucionalidad de las normas ordinarias [es] la total, definitiva y absoluta observancia del procedimiento normativo que corresponde a la norma en cuestión por su contenido material ${ }^{101} \gg$. Por ello, los poderes públicos han de respetar la Constitución ${ }^{102}$. Sin embargo, partiendo de posiciones kelsenianas del positivismo formalista radical, es posible la mutación de las normas constitucionales, siempre y cuando se lleve a cabo por los órganos legalmente establecidos y a través del respeto de sus cauces formales, aunque ello suponga una contradicción con la propia Constitución ${ }^{103}$. Además, tampoco es aceptable defender que se incumpla la Ley porque se haga habitualmente y menos defender la ilegalidad como cauce jurídico.

Adicionalmente, se denuncia por todos los grupos nacionalistas, al igual que se hiciera con fuerza en la STC 99/1986, que no se tiene en cuenta la fuerte voluntad de los vecinos para integrarse en Álava y que es indudable su voluntad de incorporación ${ }^{104}$, lo cual es indiscutido e indiscutible. No obstante, es preciso plantearse la virtualidad de la voluntad vecinal en la adopción de decisiones.

99 Cfr., Ruipérez Alamillo, J., Reforma vs. Revolución. Consideraciones desde la Teoría del Estado y de la Constitución sobre los límites materiales a la revisión constitucional, Porrúa, México, 2013, pp. 29-31.

100 Cfr., De Vega García, P., La reforma constitucional y la problemática del Poder Constituyente, Ed. Técnos, Madrid, 2011, p. 291.

101 Ruipérez Alamillo, J., Reforma vs. Revolución. Consideraciones desde la Teoría del Estado y de la Constitución sobre los limites materiales a la revisión constitucional, Porrúa, México, 2013, cit., p. 150 .

102 Íbidem, pp. 18-19, 29-30 y 148-149.

103 Íbidem, pp. 147-148.

104 El Profesor A. Sánchez Blanco, considera que esta resolución daña la legitimidad democrática para evitar dañar el funcionamiento de las instituciones. Además, considera que el Tribunal Constitucional no tiene en cuenta la situación de bloqueo a que está sometido el enclave. Cfr., SÁnchez Blanco, A, «Ajustes territoriales...», pp. 135 y 164. También, E. Belda PÉrezPedrero, «Condado de Treviño...», pp. 211-212 y 224-225. Así, este autor considera que la mencionada sentencia tiene en cuenta a los municipios, pero de forma escasa. p. 222. 
De este modo, no cabe dudar, al establecerse el principio democrático en el art. 1.1 de nuestra vigente Constitución, que la voluntad de los ciudadanos españoles es la que debe regir la organización política y administrativa, ya que es al Pueblo español al único al que corresponde decidir los modos y formas en que desea ser gobernado. Así, defendemos, junto con Rodríguez-Arana ${ }^{105}$ que el estudio jurídico-administrativo de las estructuras políticas y administrativas debe hacerse desde los ciudadanos y no desde el Estado burocrático, pudiendo participar los vecinos en todo aquello que afecte a los espacios locales, pues «los dueños de los intereses públicos locales son los vecinos ${ }^{106}$ ». Y esto no deberá estar nunca reñido con la Ley.

De este modo, es preciso analizar hasta qué punto los representantes de los ciudadanos personifican los intereses populares de su circunscripción representativa y no únicamente a los de su partido. En definitiva, se trata de dilucidar hasta qué punto los intereses políticos prevalecen sobre los democráticos. Ello significa plantearse si en la actualidad está plenamente vigente el mandato representativo, establecido por nuestra Constitución, por el cual los representantes gozan de total libertad para debatir acerca de los intereses del Pueblo, o si por el contrario, rige el mandato imperativo, es decir, los representantes están sometidos a la circunscripción, partido o grupo de personas que los eligió. Así, en primer lugar, cabe señalar, al igual que el Profesor De Vega, que los diputados están sometidos al mandato imperativo de su partido, no de su circunscripción electiva, por lo que hablar de mandato representativo forma parte de la arqueología constitucional ${ }^{107}$. Por tanto, ya no son los parlamentos o gobiernos quienes toman las decisiones, sino los comités ejecutivos de los partidos. Por ello, los partidos políticos ${ }^{108}$ son los verdaderos protagonistas de la mecánica electoral ${ }^{109}$, lo que se traduce en una mutación constitucional, dando lugar a tendencias

105 Cfr., RodrígueZ-Arana MuÑoz, J., «El Gobierno y la Administración Local en España: Sobre las alteraciones de los términos municipales con especial referencia al caso gallego», AFDUDC, 2013, pp. 131-133.

106 Íbidem, cit., p. 133.

107 Cfr., De Vega García, P., «En torno a la crisis...», p. 26, «La crisis de la representación política...», pp. 193-194 y «Significación constitucional...», p. 37.

108 Es preciso aclarar que cuando hablamos a partidos políticos nos referimos a aquellos que buscan entrar en el parlamento o ya han accedido a aquel, ya que el concepto de partido político es muy amplio y engloba también a los grupos de interés. Cfr., Hernández Bravo de Laguna, J., «Partidos políticos, Estado y Derecho: de la hostilidad a la teoría», Anales de la facultad de Derecho, no 9, 2002, pp. 74-76.

109 Además, fueron los partidos políticos los que realizaron la descentralización del Estado. Cfr., Ruipérez Alamillo, J., La Constitución del Estado de las Autonomías..., p. 201. 
oligárquicas ${ }^{110}$. Este protagonismo de los partidos políticos procede de la Constitución, ya que la misma es el resultado de un consenso entre los principales actores políticos que buscaban, en opinión de Pisarello, un modelo más gobernable que democrático ${ }^{111}$. Se trata, por tanto, de una deslocalización de la política $^{112}$. Pero esa violación del mandato representativo no es imputable a los partidos, pues los diputados son jurídicamente libres de obedecer o no al partido, por lo que tanto si se someten al partido como si no, lo hacen ejerciendo esa libertad. Si no se acepta que el diputado pueda negarse a la disciplina de partido, se estaría violando la Constitución. Sin embargo, este hecho no resta validez a las normas emanadas de la cámara parlamentaria ${ }^{113}$. Por tanto, debemos concluir que, aunque cabe cuestionar que los intereses defendidos en el Parlamento se correspondan siempre con los intereses de los ciudadanos, esas leyes son la representación formal de los intereses populares y su legalidad no puede ponerse en duda. No obstante, por lo que se refiere al caso que nos ocupa, aunque los parlamentarios votaron en bloque en las tres cámaras afectadas, lo cierto es que, en cada una de ellas, la postura fue libre, por lo que la aplicación del mandato imperativo fue solo parcial. Así, en un alarde de libertad democrática, los partidos políticos votaron diferente en función de la cámara parlamentaria en la que se encontraban, aunque dentro de cada una lo hicieron de forma unánime, pues el Parlamento representa al Pueblo en su conjunto ${ }^{114}$ y los parlamentos autonómicos a los ciudadanos de su comunidad.

Una vez aclaradas que las cámaras parlamentarias representan jurídicamente la voluntad de los territorios sobre los que gobiernan, es preciso plantearse si los municipios, como corporaciones, pueden hacer valer su voluntad frente a los órganos de decisión política o si su voluntad merma ante voluntades superiores. Así, el art. 137 de la Constitución española garantiza a los entes locales una autonomía que debe ser respetada por el legislador ordinario, tanto central como autonómico. Así, según Jellinek, las corporaciones municipales tienen territorio

110 Cfr., De Vega García, P., «La crisis de la representación política...», pp. 194-198 y 203-204 y Significación constitucional...», p. 41-45.

111 Cfr., Pisarello, G., «Constitución y Gobernabilidad: Razones de una democracia de baja intensidad», Las sombras del sistema constitucional español, en la obra colectiva de J. R. Capella (Coord.), Editorial Trotta, Madrid, 2003, p. 133.

112 Cfr., De Vega García, P., «En torno a la crisis...», p. 25 y Ruipérez Alamillo, J., El constitucionalismo democrático en los tiempos de la globalización: Reflexiones rousseaunianas en defensa del Estado constitucional democrático y social, Universidad Nacional Autónoma de México, México, 2005, pp. 180-182.

113 Cfr., Jellinek, G., Teoría General del Estado, (1911, 2a edición), Prólogo y traducción de Fernando de los Ríos, ed. Fondo de Cultura Económica, 2000, pp. 325-343.

114 Íbidem, p. 523. 
y poder, que ejercen sobre las personas, por lo que gozan de poder de imperium. Pero ese poder no es originario, como en el caso de los Estados miembros, sino derivado, lo que implica que no puede suprimir ningún Estado-miembro, pero sí municipios particulares. Además, la autonomía municipal ${ }^{115}$, según Jellinek, debe ejercerse a través de asociaciones que obran en nombre propio, no del Estado, en el cumplimiento de sus derechos ${ }^{116}$. Sin embargo, a diferencia de lo defendido por Jellinek ${ }^{117}$, su actividad, organización y esfera de acción no está fijada por la Constitución, sino que en España, actualmente, es competencia del legislador ordinario. Por otro lado, los artículos 4.6 y 5 de la Carta Europea de la Autonomía Local reconocen el derecho de toda Comunidad Local a ser consultada en todas las decisiones, especialmente cuando se trate de su ámbito territorial. Por otra parte, actualmente, de acuerdo con los arts. 59 y 75 de la Ley Orgánica del Tribunal Constitucional, los municipios pueden interponer recursos de inconstitucionalidad por conflictos de competencias, siempre que estén directamente afectados por la Ley o representen, al menos, un séptimo de los municipios existentes en el ámbito territorial de aplicación de la misma y representen, también, al menos, un sexto de la población afectada. Adicionalmente, será necesario que los municipios adopten dicha decisión por una mayoría absoluta de sus miembros. Además, los municipios también pueden acudir al Tribunal Contencioso-Administrativo ante los actos administrativos sin valor de ley que lesionen su autonomía local, de acuerdo con el art. 63,2 LBRL. Por tanto, cabe concluir que, en la actualidad, los municipios tienen garantizada tanto su participación como medios de protección ante toda decisión que pueda alterar su identidad territorial. Y no cabe dudar, en modo alguno, que los municipios del Enclave de Treviño no fueron tenidos en cuenta para llevar a cabo la alteración territorial, ya que el único requisito para poner en marcha el procedimiento es el acuerdo de una o ambas corporaciones, reconocido por ambos Estatutos, adoptado por mayoría absoluta y, además, es preciso el referéndum de los vecinos de ambos municipios. Por tanto, cabe concluir que la voluntad de las corporaciones afectadas está asegurada en ambos procesos.

Aclarado lo anterior, es preciso plantearse si la voluntad de los vecinos treviñeses debe acotarse y restringirse a los procedimientos establecidos en la Ley. Así, el Pueblo es, desde la ideología democrática, el titular indiscutible de la

115 Para una mejor comprensión de la autonomía municipal y provincial. Vid., Arroyo GIL, A., «Autonomía Local. Una reflexión constitucional», XIII Congreso anual de la Asociación de Constitucionalistas de España: «La Organización Territorial del Estado, hoy», Zaragoza, 19 y 20 de diciembre de 2015 .

116 Íbidem, pp. 569-570.

117 Íbidem, pp. 346-369. 
soberanía de un Estado ${ }^{118}$. De este modo, no puede renunciar jamás a esa soberanía, pues sería un contrato nulo. Por tanto, en el caso hipotético de que decidiese hacerlo, éste seguirá siendo el soberano, pudiendo recuperar el ejercicio efectivo de su poder en cualquier momento de forma completamente legíti$\mathrm{ma}^{119}$. Y es, precisamente aquí, en la necesidad de hacer reales y efectivas las ideas de Libertad y Democracia, donde se encuentra la virtualidad de la Constitución ${ }^{120}$, ya que la misma permite que la voluntad del Pueblo alcance la cúspide normativa, imponiéndose por igual a gobernantes y gobernados. De esta forma, conjugando el vivere libero y vivere civile maquiavelista ${ }^{121}$, la Ley, voluntad de todos los ciudadanos, se impone por encima de todos ellos por igual $^{122}$. No obstante, si el Pueblo quisiera ejercer la soberanía de forma permanente, lo que en realidad estaría haciendo sería confundir la soberanía con el gobierno, lo que no se traduce necesariamente en un aumento de la legitimidad si ello no es parejo a un absoluto respeto a la Ley por parte del gobierno ${ }^{123}$. Por tanto, en palabras del Profesor Ruipérez, no hay Democracia sin Libertad ni Libertad sin Democracia ${ }^{124}$. De esta forma, la única garantía posible de garantizar el respeto a la voluntad popular es que la Ley derive de ésta, y todos se sometan a ella, pues los hombres sólo son libres cuando obedecen las leyes que

118 Vid., Cabanas Veiga, M., «La reforma constitucional del 2011 y la Teoría del Poder Constituyente», ADFUDC, nº 18, 2013, pp. 152-154.

119 Cfr., Fondevila Marón, M., La disolución de la soberanía en el ámbito estatal. El proceso de integración europea. Precedido por J. Ruipérez Alamillo, "Prolegómenos al Estudio de la disolución de la soberanía del Pueblo en el proceso de integración europea, y algunas de sus consecuencias jurídicas y políticas», REUS, Madrid, 2014, pp. 465-473.

${ }^{120}$ Cfr., Ruipérez Alamillo, J., Libertad civil e ideología democrática: de la conciliación entre Democracia y Libertad a la confrontación liberalismo-Democracia, Universidad Nacional Autónoma de México, México, 2008, p. 22. y Reforma vs. Revolución..., p. 168. En este mismo sentido, J. J. Rousseau defendía que la finalidad de toda legislación debe ser la Libertad y la Igualdad. Cfr., Rousseau, J.J., El contrato social, (1762), traducido por Enrique López Castellón, Edicciones P. P. P., Madrid, 1985, pp. 92 y 97.

121 Cfr., De Vega García, P., «La Democracia como proceso. Algunas reflexiones desde el presente del republicanismo de Maquiavelo», Eds: A. Guerra y J. F. y otros. Alternativas para el siglo XXI. I Encuentro en Salamanca, Sistema, Madrid, 2003, pp. 469-479 y Ruipérez AlamiLlo, J., El constitucionalismo democrático... p. 177 y Libertad civil e ideología democrática, Universidad Nacional Autónoma de México, México, 2008, pp. 23-27.

122 En relación con esto, J. J. Rousseau defendía que cada ciudadano se da sus propias leyes y se somete a las mismas a través del acto de asociación. Rousseau, J. J., Emilio o de la educación, (1762), traducido por Luis Aguirre Prado, Editorial EDAF, 1985, pp. 532-533.

123 Cfr., Rousseau, J. J., El contrato social..., pp. 81-82 y 106-107.

124 Cfr., Ruipérez Alamillo, J., Libertad civil e ideología democrática..., p. 22. También cfr., DE Vega García, P., «La Democracia como proceso..., pp. 469-479. 
se dan a sí mismos ${ }^{125}$. En definitiva, en contra de las falsas opiniones que consideran que la Democracia es hacer prevalecer los intereses políticos sobre la Ley, expresión de la voluntad de todos los ciudadanos, la verdadera Democracia es, como expone Heller, el predominio del Pueblo como unidad sobre el Pueblo como pluralidad ${ }^{126}$. Por ello, ocioso debería ser aclararlo, cabe descartar cualquier interpretación soberanista de la secesión, como han hecho algunos parlamentarios, por estar ésta expresamente prohibida por la vigente Constitución ${ }^{127}$. Ni siquiera se trata, en este caso, de dar participación a la voluntad ciudadana en la conformación de la organización territorial del Estado, sino sólo en la organización territorial de la Administración.

En conclusión, aquella decisión de los habitantes de Treviño que incumpliese la Ley no sería más democrática, sino todo lo contrario, pues se estarían imponiendo 2000 ciudadanos al Pueblo español, cuya voluntad está consagrada en la Constitución. Así, tanto a la misma como al bloque de constitucionalidad han de estar sometidos tanto gobernantes como gobernados. Por tanto, para que la voluntad de los vecinos de Treviño sea verdaderamente democrática es preciso que siga los cauces legalmente establecidos, respetando, ante todo, la Constitución. De este modo, las pretensiones treviñesas son absolutamente legítimas y democráticas mientras las mismas respeten la voluntad del resto de los habitantes españoles o, de lo contrario, se estarían imponiendo tiránicamente al resto de sus ciudadanos, ya que, como vecinos burgaleses, los treviñeses también participaron en la ratificación y elaboración de la Constitución, a través de sus representantes provinciales. De este modo, es preciso dejar constancia de que el referéndum no es un acto soberano de autodeterminación, sino un acto de control de los gobernantes municipales, para evitar que realicen actos en contra de la voluntad de sus vecinos pero, en todo caso, el referéndum debe respetar la Ley ${ }^{128}$. Y es que, como sostiene Montesquieu, si no se respeta la ley, el Estado se desmorona ${ }^{129}$ pues, como expone Rousseau, «Allí donde cesa el vigor de las leyes y la autoridad de sus defensores no puede haber seguridad ni libertad para nadie ${ }^{130} »$.

125 Cfr., Ruipérez Alamillo, J., Libertad civil e ideología democrática..., p. 30.

126 Cfr., Heller, H., Europa y el fascismo, Traducido del alemán por Francisco J. Conde, Editorial Comares, Granada, 2006, p. 3.

127 Cfr., Ruipérez Alamillo, J., Reforma vs. Revolución...», pp. 73-77 y 85, La Constitución del Estado de las Autonomías..., pp. 141-147, Formación y determinación..., pp. 118-119 y también Fondevila Marón, M., «Derecho a decidir y soberanía. A propósito de la STC 42, 2014, de 25 de marzo», TRC., núm. 34, 2014, pp. 600-605.

128 Cfr., De Vega García, P., La reforma constitucional y la problemática..., p. 112.

129 Cfr., Montesquieu, Del espíritu de las leyes, (1748), traducido por Pedro de Vega y Mercedes Blázquez Polo, Editorial Técnos, Madrid, 1985, p. 19.

130 Rousseau, J. J., Discurso sobre el origen..., cit., 103. 


\section{IV. ¿REFORMA ESTATUTARIA O LEY ORGÁNICA?}

De todo ello se deduce, por tanto, que las Comunidades Autónomas son competentes para realizar las alteraciones territoriales de sus municipios con total libertad, de acuerdo con el art. 148,1.2 ${ }^{\text {a }}$, siempre y cuando dicha alteración no altere los límites provinciales ${ }^{131}$, pues para ello sería necesario que la misma fuese aprobada por las Cortes Generales mediante Ley Orgánica, de acuerdo con el art. 141.1 de la Constitución española. Sin embargo, el artículo 147.2.b de la Constitución establece que todo Estatuto de Autonomía debe contender, como mínimo, la delimitación de su territorio, tanto su definición como sus posibles alteraciones $^{132}$, cuya regulación solo puede alterarse por reforma estatutaria o por una reforma constitucional. Se trata, en palabras del Profesor Ruipérez, de una «reserva absoluta» de los Estatutos de Autonomía en el momento de su constitución $^{133}$, de acuerdo con el Tribunal Constitucional ${ }^{134}$, el cual establece que «(...) la aprobación de los Estatutos de Autonomía por Ley Orgánica no constituye un simple revestimiento formal de una norma propiamente autonómica, sino la incorporación, definitiva y decisiva, de la voluntad del legislador estatal a [... la la norma institucional básica de cada Comunidad Autónoma» ${ }^{135}$. Por tanto, el Poder central no tiene un poder absoluto en materia de alteración territorial provincial, ya que no puede actuar unilateralmente cuando dicha alteración afecte a lindes autonómicos, sino que para ello necesita contar con la voluntad de las Comunidades Autónomas afectadas. Así, es esta rigidez estatuyente la que otorga a los Estatutos de Autonomía el carácter de normas cuasi-supremas ${ }^{136}$. Por tanto, es obvio que el Derecho constitucional español excluyese la posibilidad de que los municipios puedan elegir libremente su pertenencia provincial, pues de lo contrario la regulación administrativa del Estado quedaría fuera de su competencia $^{137}$.

131 El art. 12 de la Constitución de 1931 permitía la disolución de las provincias si así lo deseaban las regiones.

132 Cfr., STC 99/1986. Fundamento Jurídico 4.

133 Cfr., Ruipérez Alamillo, J., Formación y determinación..., p. 116. Así, por reserva absoluta entendemos que para abordar dicha modificación es necesaria la reforma de los Estatutos, quedando excluido de la misma el legislador ordinario, tanto central como autonómico. Por reserva relativa entendemos, sin embargo, aquella en la que no es necesaria la reforma estatutaria, sino que el desarrollo debe ser realizado por el legislador ordinario autonómico, pero no por el central.

134 Cfr., STC 99/1986. Fundamento Jurídico 1.

135 Íbidem.

136 Cfr., Ruipérez Alamillo, J., La Constitución del Estado de las Autonomías..., p. 317.

137 Cfr., Belda Pérez-Pedrero, E., «Condado de Treviño...», p. 225. 
De esta forma, como la reforma estatutaria del Estatuto de Castilla y León solo puede iniciarse por voluntad del parlamento autonómico ${ }^{138}$, quedando excluido de la iniciativa el poder central, de acuerdo con el art. 91 del actual Estatuto de Autonomía de Castilla y León, éste deberá, si realmente desea realizar una alteración que modifique los límites autonómicos, llevar a cabo negociaciones con su parlamento y gobierno para que inicien la reforma estatutaria o el procedimiento que establezcan sus Estatutos. Sin embargo, el Estado sí podrá iniciar la reforma estatutaria del Estatuto Vasco, de acuerdo con su art. 46, pero todavía es necesario, para que pueda aprobarse por Ley Orgánica, que la misma sea adoptada antes en sede regional y, posteriormente, ser aprobada por referéndum. Además, en ningún caso será posible la reforma estatutaria por iniciativa popular ${ }^{139}$. Por otra parte, en caso de que el proyecto de reforma estatutaria sea aprobado en sede regional, las Cortes Generales podrán introducir cuantas modificaciones consideren precisas, pudiendo llegar a vaciar de competencias a la Comunidad Autónoma, pero siempre respetando el contenido mínimo ${ }^{140}$ de autonomía ${ }^{141}$. Lo mismo sucederá si el partido mayoritario en el parlamento regional y central es el mismo ${ }^{142}$, llevándose a cabo una reforma estatutaria no por motivos inaplazables y objetivos, sino por razones partidistas y coyunturales ${ }^{143}$. Y al hablar de contenido mínimo, estamos hablando de límites materiales a la reforma estatutaria, ya que, según el Profesor Ruipérez, negar los límites materiales a la reforma supone eliminar el principio de rigidez ${ }^{144}$, pues aunque el poder de reforma estatutaria puede modificar todos los artículos estatutarios, existen determinados contenidos que no puede eliminar, pues de

138 Esto solo es aplicable a los Estatutos de Autonomía de Castilla León y al del País Vasco, pero no se puede afirmar de la práctica totalidad de los Estatutos españoles, como señala el Profesor J. Ruipérez Alamillo, Cfr., Ruipérez Alamillo, J., Formación y determinación..., pp. 169-176.

139 Cfr., Ruipérez Alamillo, J., Formación y determinación..., p. 173.

${ }^{140}$ La doctrina del Tribunal Constitucional enfatiza el carácter de la autonomía local, en cuanto derecho a participar en la gestión de los intereses respectivos de estas comunidades, matizando en su STC 170/89 de 19 de octubre, que: «(...) sería contrario a la autonomía municipal una participación inexistente o meramente simbólica que hiciera inviable la participación institucional de los Ayuntamientos».

141 Cfr., Ruipérez Alamillo, J., La Constitución del Estado de las Autonomías..., pp. 167 y 174 .

142 En el caso del Estatuto de Castilla y León, en su art. 91.4, se recoge la posibilidad de retirar la reforma en cualquier momento, por lo que sólo se podrá realizar dicho vaciamiento si en ambas Cámaras domina el mismo partido mayoritario.

143 Lo dicho por el Profesor J. Ruipérez Alamillo, respecto de la Constitución, cabe también afirmarse respecto de los Estatutos de Autonomía, participes de la rigidez constitucional. Cfr., Ruipérez Alamillo, J., Formación y determinación..., p. 64.

${ }^{144}$ Cfr. Ruipérez Alamillo, J., Reforma vs. Revolución..., p. 104. 
lo contrario estaría eliminando la propia autonomía política de las Comunidades Autónomas. Por tanto, es constitucionalmente, aceptable y posible, modificar los Estatutos de Autonomía, pero no incumplirlos, pues mientras conserven su vigencia deberán respetarse siempre ${ }^{145}$. Así, las únicas leyes válidas contrarias a los Estatutos son aquellas derivadas de su reforma o de la Constitución. Las demás, deberán ser declaradas inconstitucionales ${ }^{146}$. Por tanto, aunque el Estado pueda introducir cuantas enmiendas precise, al llevar a cabo la reforma, podemos concluir, al igual que el Profesor Ruipérez, que la reforma estatutaria no es una mera Ley Orgánica, por no ser éste un acto unilateral del poder central, sino que en la misma han de concurrir tanto la voluntad autonómica, adoptada a través del procedimiento establecido en sus Estatutos, como la voluntad del poder central, aprobada mediante Ley Orgánica, de acuerdo con el art. 147.3 de la Constitución española, y la única posibilidad que tiene el Estado de alterar los Estatutos de forma unilateral es a través de la reforma constitucional $^{147}$.

Ahora bien, de acuerdo con la interpretación del Tribunal Constitucional, el Estatuto de Autonomía de Castilla y León establece, en su art. 2, una definición territorial espacial de aplicabilidad de las disposiciones y actos normativos de la Comunidad Autónoma, por lo que la alteración territorial que no signifique «una alteración de la configuración provincial de la Comunidad Autónoma no entraña [...] una revisión formal del Estatuto ${ }^{148}$ », es decir, no importan los municipios que formen sus provincias mientras éstas sigan existiendo y conserven su identidad, «aun cuando supongan también una modificación en el territorio de la Comunidad» ${ }^{149}$, estableciendo su propio Estatuto los procedimientos para llevar a cabo dicha alteración. Por otro lado, el art. 2.2 del Estatuto de Autonomía del País Vasco establece una delimitación natural del territorio ya que, al nacer como Comunidad Autónoma, definió sus límites como los actuales, por lo que solo podría modificarlos a través de una reforma estatutaria o, como es el caso, a través de reglas específicas para llevar a cabo dichas alteraciones ${ }^{150}$. Por tanto, cabe concluir, según la interpretación de la jurisprudencia constitucional, que las alteraciones de los límites territoriales autonómicos han de hacerse por los procedimientos establecidos en sus Esta-

\footnotetext{
145 Cfr., Ruipérez Alamillo, J., La Constitución del Estado de las Autonomías..., p. 147.

146 Íbidem, pp. 319 y 327.

147 Cfr., Ruipérez Alamillo, J., Formación y determinación..., pp. 125 y 169-172.

148 Cfr., STC 99/1986. Fundamento Jurídico 5.

149 Cfr., STC 99/1986. Fundamento Jurídico 4 y 5.

150 Cfr., STC 99/1986. Fundamento Jurídico 4 y 5.
} 
tutos o, en su defecto, por reforma estatutaria ${ }^{151}$, por lo que la alteración territorial del enclave no supondría reforma estatutaria de ninguno de los Estatutos afectados. No obstante, esta interpretación tiene una consecuencia importante. Así, mientras que para realizar la alteración territorial través de la reforma estatutaria, la Comunidad Autónoma afectada corre el riesgo de que el Parlamento central pueda llevar a cabo cuantas enmiendas considere necesarias, en el caso de que la misma se realice a través de los propios procedimientos estatutarios, la única posibilidad que tiene el poder central es aceptar o rechazar la propuesta de modificación territorial, pero no llevar a cabo modificación alguna de sus Estatutos.

De este modo, debemos concluir que los Estatutos de Autonomía pueden establecer el régimen jurídico a través del cual se lleva a cabo las secesiones o las agregaciones, sin necesidad de realizar reforma estatutaria ${ }^{152}$, como es el caso que nos ocupa. Pero también puede suceder que quiera llevarse a cabo una alteración territorial y uno o ambos Estatutos careciesen de dichos procedimientos. En ese caso, y de acuerdo con la sentencia 99/1986, será necesario llevar a cabo la reforma estatutaria, de acuerdo con los procedimientos en ella establecidos y, si el Estatuto no recogiese dicha reforma, no por ello pierde rigidez. Así, coincidiendo plenamente con el Profesor Ruipérez, los Estatutos pueden contener o no el procedimiento de reforma, pues es contenido voluntario pero, en cualquier caso, es necesario que en el mismo concurran las voluntades de las organizaciones centrales y regionales, no pudiendo realizarse unilateralmente por ninguna de ellas. Por tanto, será preciso, en ese caso, que la reforma sea aprobada por mayoría simple en sede regional y por Ley Orgánica en sede central ${ }^{153}$, extendiéndose la rigidez constitucional a los Estatutos de Autonomía para proteger a las colectividades-miembro ${ }^{154}$. De todo lo hasta aquí dicho cabe afirmar que, si nunca se llegase a aprobar la contenciosa Disposición Transitoria, la agregación no se haría a través del Estatuto vasco, sino que sería preciso reforma estatutaria por el procedimiento establecido y, en su defecto, dicha decisión debería ser

151 No creemos que sea correcta la interpretación del Tribunal Constitucional por la cual la modificación territorial que no implique la supresión de la identidad provincial de una de sus provincias no requiera reforma estatutaria, pues la alteración territorial autonómica debe realizarse a través de los procedimientos establecidos en los Estatutos, ya que el propio art. 148.1.2 establece que la alteración territorial debe regularse por sus Estatutos. STC 99/1986. Fundamento Jurídico 5 .

152 Cfr., Ruipérez Alamillo, J., Formación y determinación..., p. 130.

153 Cfr., Ruipérez Alamillo, J., La Constitución del Estado de las Autonomías...., pp. 306-3012 y Formación y determinación..., pp. 96-97.

154 Cfr., Ruipérez Alamillo, J., Formación y determinación..., pp. 169-171 y La protección constitucional de la autonomía, Editorial Tecnos, Madrid,1998. 
adoptada por mayoría simple y aprobada, posteriormente, por las Cortes Generales. Únicamente se podría aplicar el Estatuto Vasco si Treviño, como parte de Burgos, no hubiera accedido a la autonomía.

Así, como antes se expuso, la reforma constitucional es la única posibilidad que se le reconoce al Estado para reformar los Estatutos de Autonomía unilateralmente ya que, una vez aprobada ésta, los Estatutos deberán modificarse en todo aquello que sea contrario a dicha reforma para adaptarse a la misma o, de lo contrario, mantendrán su inconstitucionalidad ${ }^{155}$. De esta forma, mientras que para suprimir la autonomía municipal o provincial es preciso acudir al procedimiento de reforma establecido en el art. 167 de la vigente Constitución, de acuerdo con el Profesor Ruipérez ${ }^{156}$, nuestro ordenamiento jurídico, propio de un Estado federal, eleva el grado de protección de la autonomía regional al exigir para su supresión llevar a cabo el gravosísimo procedimiento del art. 168, pero tampoco es posible suprimir dicha autonomía por reforma constitucional, ya que ello supondría eliminar la forma de Estado federal, lo que se traduciría en una ruptura constitucional. De esta forma, nos encontramos ante un límite material de la Constitución, por lo que únicamente el Poder Constituyente podrá suprimirla ${ }^{157}$. Así, por ser la garantía constitucional de la autonomía la principal característica que define a un verdadero Estado federal ${ }^{158}$ y que permite, a los Estados-miembros, contar con mecanismos adecuados para hacer frente a las intromisiones de

155 Así, afirma el Profesor J. Ruipérez Alamillo, que en la reforma constitucional no es necesario contar con el consentimiento de las Comunidades Autónomas. Sólo es preciso una mayoría de dos tercios en el Congreso y en el Senado para llevar a cabo el procedimiento del art. 167 y de tres quintos de ambas Cámaras para llevar a cabo el procedimiento del art. 168. Además, en el procedimiento del art. 167, si no hay acuerdo de ambas cámaras, basta con que en la segunda vuelta se apruebe por dos tercios del Congreso y mayoría absoluta del Senado. Cfr., RuIPÉREZ Alamillo, J., Formación y determinación..., p. 32 y 90. También La Constitución del Estado de las Autonomías..., pp. 210-214.

156 Cfr., Jellinek, G., Teoría General del Estado, (1911, 2ª Edición, Prólogo y traducción de Fernando de los Ríos, Ed. Fondo de Cultura económica, 2000, pp. 56-58. y Ruipérez Alamillo, J., Formación y determinación..., pp. 24-51 y 79.

157 Para una mejor comprensión de la facultad del Poder Constituyente en nuestro Código Fundamental actual, Vid., DE VEGA GARcía, P., La reforma constitucional y la problemática ... y DE Vega García, P., «La reforma constitucional como defensa de la Constitución y la Democracia», Ponencia presentada a las II Jornadas de Derecho Constitucional: "Reforma de la Constitución», Fundación Jimenez Abad de Estudios Parlamentarios y del Estado Autonómico y Centro Asociado de la UNED de Barbastro, Huesca, 27 y 28 Octubre 2006, Ruipérez Alamillo, J., Reforma vs. Revolución..., Fondevila Marón, M. La disolución de la soberanía... y por comodidad, CaBANAS Veiga, M., «La reforma constitucional del 2011 y la Teoría del Poder Constituyente», ADFUDC, $\mathrm{n}^{\mathrm{o}} 18,2013$.

158 Cfr., Ruipérez Alamillo, J., La Constitución del Estado de las Autonomías..., pp. 242-244. 
las autoridades centrales en su esfera de poder, una reforma constitucional no podrá, y mucho menos una reforma estatutaria, suprimir el contenido del art. 147.2.b), ya que el territorio es un elemento constitutivo de los entes territoriales. Por tanto, es preciso excluir cualquier hipotética propuesta de reforma constitucional que proponga suprimir dicho precepto constitucional para solucionar los posibles problemas de los enclaves, pues sin la protección constitucional del territorio regional no hay verdadera autonomía federal ${ }^{159}$. Cabría incluso realizar una reforma constitucional para establecer una Disposición Transitoria en la Constitución que estableciese una autorruptura constitucional para ese caso concreto, pero su virtualidad jurídica sería enormemente cuestionable ${ }^{160}$. Otra hipotética posibilidad de solucionar el conflicto a través de la reforma constitucional sería exigir la existencia de continuidad territorial en la Comunidad Autónoma, ya que actualmente el art. 143 de la Constitución española sólo exige que sean provincias limítrofes, siendo suficiente con que las mismas formen un territorio compacto $^{161}$. Sin embargo, ello podría aumentar aún más los problemas interpretativos con respecto a los archipiélagos o los diferentes enclaves que se encuentran en una situación similar a Treviño. En cualquier caso, sería una muestra de una absoluta negligencia y decadencia política tener que acudir a la reforma constitucional por no saber solucionar un bloqueo político por la vía del consenso ${ }^{162}$ pues, como propone Rousseau, «seamos sencillos obrando bien ${ }^{163} »$.

Por tanto, cabe concluir que, para llevar a cabo la alteración provincial del Enclave de Treviño ${ }^{164}$, sería necesario realizar un único procedimiento. Así, el

159 Debemos descartar, por tanto, la propuesta del Profesor A. Sánchez Blanco, de solucionar el conflicto permitiendo a los enclaves cualquier vía para la secesión, en la que no es necesario siquiera que se recojan en los Estatutos. Cfr., SÁNCHEZ BLANCO, A, «Ajustes territoriales...», pp. 1139-141.

160 Algo similar propone el Magistrado Leguina, en su voto particular de la STC 99/1986, al defender la aplicación de la disposición impugnada en todo aquello que no entre en contradicción con lo establecido en el art. 8 del Estatuto vasco, pero manteniéndose su plena vigencia para los demás procedimientos de segregación de municipios enclavados en otras Comunidades Autónomas, por lo que está defendiendo un quebrantamiento constitucional, ya que defiende que una norma estatutaria, como parte del bloque de constitucionalidad, se inaplique para un caso concreto pero mantenga su vigencia para los demás casos. Sin embargo, las únicas autorrupturas aceptables son aquellas que establece la propia Constitución. Cfr., DE VEGA GARcía, P., La reforma constitucional y la problemática..., pp. 173-175.

161 Cfr., Ruipérez Alamillo, J., Formación y determinación..., p. 113.

162 En cualquier caso, las Cortes actuales se muestran más favorables por el cumplimiento de la legislación estatutaria y constitucional, en relación a esta problemática. «Del Parlamento vasco...»

163 Rousseau, J. J., Emilio o de la educación, (1762), traducido por Luis Aguirre Prado, Editorial EDAF, 1985, cit., p. 231.

164 Pese a sus críticas a la sentencia 99/1986 y a defender que el procedimiento correcto sería el establecido en el Estatuto vasco, el Profesor E. Belda defiende el cumplimiento de la Ley cons- 
mismo comenzaría con los acuerdos municipales adoptados por una mayoría de dos tercios en cada una de las corporaciones municipales o, en todo caso, por su mayoría absoluta, tal y como establece la Disposición Transitoria Tercera del Estatuto castellano-leonés. De esta forma, si dicho acuerdo no estableciese la segregación sin destino, sino un destino concreto, se entenderán que en el mismo se cumple tanto el requisito castellano-leonés como el vasco, pues las mayorías del primero colman las del segundo. Lo mismo ocurriría con la emisión de los informes de la Diputación de Burgos y de la Comunidad Autónoma de Castilla y León, segundo requisito del procedimiento, ya que si los mismos contemplan la segregación de su territorio y su posterior agregación al País vasco, se entenderá que se está dando cumplimiento a ambos preceptos estatutarios. Igualmente, si el referéndum se plantea como una decisión entre permanecer en Burgos o agregarse a Álava, y no simplemente segregarse, también deberá considerarse cumplido el requisito vasco. Finalmente, el acuerdo de agregación debe ser adoptado por el Parlamento vasco y aprobado por las Cortes Generales mediante Ley Orgánica. De esta forma, en nuestra opinión, siempre digna de ser puesta en cuestión, no se trata tanto de un vaciamiento del contenido del art. 8 del Estatuto vasco, ya que, como hemos visto, siempre que se plantee como una futura incorporación a su territorio, se estaría tratando, en realidad, de una aplicación simultanea de dos preceptos en un mismo procedimiento. Por tanto, lejos de ser un problema que la regulación de ambos preceptos sea tan similar, ello permite simplificar los trámites de segregación y posterior agregación al País Vasco. De esta manera, si se incumple uno solo de los procedimientos establecidos en ambos Estatutos de Autonomía, dicha alteración sería inconstitucional, no pudiendo ser suplido ese vicio de ilegalidad por una eventual aprobación del Parlamento Nacional, pues éste no puede alterar unilateralmente lo contenido en los Estatutos. Ahora bien, si tanto el acuerdo municipal como los informes y el referéndum se plantean como una segregación sin destino, sin duda será preciso volver a cumplir los requisitos del Estatuto vasco.

Así las cosas, cabe plantearse qué sucedería si dicha agregación se plantea sin destino o, siguiendo el procedimiento único, finalmente es rechazada por la Comunidad Autónoma destinataria. De esta forma, podría pensarse que, en ese caso, el territorio de Treviño, al no pertenecer a ninguna Comunidad Autónoma, perdería su autonomía y, por tanto, pasaría a formar parte del territorio nacional bajo la dirección del poder central. Por ello, el Enclave de Treviño pasaría a formar parte del régimen de «territorio federal» convertido en un distrito federal, careciendo de cualquier autonomía, por lo que se rigiría por el Derecho

titucional y estatutaria. Cfr., Belda Pérez-Pedrero, E., «Condado de Treviño...», p. 225. 
estatal. Así, es posible, de acuerdo con la Constitución española, que junto con los territorios que accediesen al autogobierno, existiesen otros que no hubieran accedido al mismo ${ }^{165}$. Posteriormente, el Estado podría optar entre dejarlo bajo su custodia o permitirle el acceso a la autonomía, en virtud del art. 144. b), por el cual los territorios que no se encuentran integrados en la organización provincial podrán acceder a la autonomía. Así, Treviño pasaría a tener un régimen autonómico similar a Ceuta y Melilla, accediendo al status de una corporación local de régimen especial. Sin embargo, esta opción no la creemos correcta para el caso del enclave que nos ocupa. En primer lugar, porque si se siguiese un único procedimiento, el acto de segregación/agregación no tendría lugar hasta que fuese aprobado por las Cortes Generales mediante Ley Orgánica. En segundo lugar, la Disposición Transitoria Tercera castellano-leonesa establece, en su apartado 2, que «en todo caso, el resultado de este proceso quedará pendiente del cumplimiento de los requisitos de agregación exigidos por el Estatuto de la Comunidad Autónoma a la que se pretende la incorporación», por lo que mientras no se agregase a ninguna otra Comunidad, en caso de no seguir un único procedimiento, Treviño seguiría formando parte de Castilla y León, y ello sería así aunque se hubiera seguido una segregación sin destino, por lo establecido en dicha disposición ${ }^{166}$.

Sin embargo, no cabría afirmar lo mismo cuando no existiese dicha cláusula y el enclave se segregase sin destino, pues ese territorio sí pasaría a depender del Estado central. De esta forma, se aprobaría la segregación territorial, bien a través de la reforma estatutaria o bien por los procedimientos establecidos en su Estatuto, debiendo aprobarse, en cualquier caso, por las Cortes Generales mediante Ley Orgánica. Así, una vez segregado el enclave, podría suceder que el otro territorio se negase a reformar su Estatuto o iniciar el procedimiento para agregarlo, pasando el enclave a formar parte del territorio federal. No obstante, por no estar regulado este supuesto ni en la legislación constitucional ni autonómica, ni tampoco estar resuelto por la jurisprudencia, nos encontramos ante una laguna jurídica. Además, no creemos que la aplicación del mencionado precepto 144 . b) antes expuesta sea la más correcta, pues es cuestionable que pudiera ser aplicado a dicha eventualidad, ya que es dudoso que Treviño pudiera acceder al autogobierno y que nos hallásemos ante una Comunidad de Auto-

165 Cfr., Ruipérez Alamillo, J., Formación y determinación..., pp. 106-107.

166 Nos distanciamos así de la opinión del Profesor E. Belda, para quien si el País vasco o las Cortes generales rechazasen la agregación, Treviño se quedaría en «tierra de nadie». Cfr., BELDA PÉrez-Pedrero, E., «Condado de Treviño...», p. 204. 
nomía gradual, la cual puede acceder primero a las competencias del art. 148.1 de la Constitución española para, pasados 5 años, acceder a las del art. 149.1.

Por último, cabe plantear el hipotético caso de que, una vez incorporado en Álava, Treviño quisiese formar parte de la provincia burgalesa de nuevo. Así, ni el Estatuto vasco ni el castellano-leonés recogen un precepto específico, pues el primero carece de uno para segregar municipios y el segundo carece de otro para agregarlos. Por ello, en caso de que no existiese un fuerte resentimiento político por parte de Castilla y León, aceptando de nuevo a sus antiguos vecinos, sería preciso una reforma estatutaria de ambos Estatutos de Autonomía, no siendo necesaria una tercera Ley Orgánica, pues se entendería cumplido el requisito del art. 141 de la Constitución española con las reformas estatutarias ya realizadas. No obstante, no conviene entrar en mayor detalle en dicha problemática pues, en palabras de Jellinek, «(...) lo que es imposible políticamente, no puede ser seriamente objeto de investigación jurídica ${ }^{167} »$.

\section{CONCLUSIÓN}

Así, desde un punto de vista psicológico y sociológico, los ciudadanos pueden sentirse pertenecientes a un Pueblo, provincia, comarca, corporación o aldea, pero desde el punto de vista político y constitucional sólo hay un único Pueblo, el Pueblo español, el cual es el único que puede decidir sobre el futuro de su vida en común y los modos y formas de organizarse a nivel estatal ${ }^{168}$. Cosa distinta es que la Constitución, obra del Pueblo, permita a los ciudadanos de las Comunidades Autónomas autonormarse en las competencias de sus respectivos territorios, respetando, ocioso debería ser volverlo a poner de manifiesto, la Norma Fundamental del ordenamiento constitucional español: la Constitución de 1978. Por tanto, tan legitima es la defensa de la pertenencia de Treviño a Burgos como a Álava.

Así las cosas, los habitantes de Treviño se ven en medio de un conflicto derivado del siempre polémico debate independentista, entre las reivindicaciones forales y la defensa acérrima de la unidad de España, por lo que terminan siendo víctimas de un conflicto en el cual, como ya sucedió en otras ocasiones, la contienda se salda con la parálisis jurídica de los procedimientos democráticos debido a una discrepancia política, a través de cautelas que impidan incumplir la Norma Fundamental. Cabe concluir, por tanto, que nos hayamos ante un indudable conflicto que no puede solucionarse políticamente sin llegar a un

167 Cfr., Jellinek, G., Teoría General del Estado..., cit., pp. 56-57.

168 Cfr., Fondevila Marón, M., «Derecho a decidir y soberanía...», pp. 587-606. 
consenso. No es posible afirmar, por tanto, que el procedimiento estatutario actual impida la secesión pues, precisamente con ella, se busca conjugar la voluntad de las diferentes instancias implicadas, sino que es la actual coyuntura política la que impide dicha secesión. De esta forma, la Democracia, como voluntad de los ciudadanos, debe conjugarse con la Libertad, entendida como el respeto a la Ley, pero una no debe prevalecer sobre la otra. Por tanto, lo importante es que tanto para su segregación como para su agregación se sigan los cauces legalmente establecidos, pues de lo contrario, al vulnerarse la Ley, se estaría perdiendo toda legitimidad. Ello se debe a que las circunstancias coyunturales políticas pueden cambiar ${ }^{169}$, pero dichos cambios no pueden afectar a la correcta aplicación de la Ley. Así, de acuerdo con los principios rousseaunianos, los gobernantes únicamente pueden llevar a cabo aquellas actuaciones permitidas por la Ley, quedando fijados legalemente sus competencias. Por tanto, de llevarse a cabo la propuesta vasca, se estaría vulnerando la Constitución española al llevar a cabo una modificación material de la misma sin acudir al adecuado procedimiento de reforma. En definitiva, solo caben dos posibilidades: o llevar a cabo la secesión del enclave a través del procedimiento establecido en ambos Estatutos, o modificar el procedimiento estatutario de secesión a través del más escrupuloso respeto a la Constitución y a sus procedimiento de reforma estatutaria, por lo que las propuestas que se aparten de la mismas lo único que hacen es oscurecer tan simple determinación. Y es que, lo que sucede, como con absoluto acierto y claridad denuncia el Profesor De Vega, es que «en las ciencias sociales se simplifica lo complejo y se complica lo simple ${ }^{170} »$. No es posible, dentro de lo estrictamente jurídico, establecer una determinada solución al problema, pues ello supondría entrar en el terreno de lo político, lo cual está vedado para cualquier profesional de las ciencias jurídicas.

No negaremos, sin embargo, que esta propuesta, aún en su amplitud e indeterminación, es colosal en términos políticos actuales pero, que duda cabe, es la mejor solución, creemos, a dicho conflicto pues, en palabras de Cicerón, «lo que más engaña a los incautos y perjudica con mucha frecuencia a la república es esa opinión según la cual se dice que una cosa es verdadera y justa, pero se niega que sea realizable ${ }^{171}$ » pues sostiene Rousseau, «existen gentes para quienes todo lo que es grande parece quimérico y que, en su baja y vil razón, no conocerán jamás lo que puede sobre las pasiones humanas la misma locura de la virtud ${ }^{172}{ }_{»}$.

169 Sería posible que el parlamento vasco dejase de estar interesado en la anexión de Treviño o que el parlamento castellano-leonés decidiese defender la segregación del enclave.

170 De Vega García, P., «En torno a la crisis...», cit., p. 26.

171 Cicerón, M. T., Las Leyes, cit, pp. 229-231.

172 Rousseau, J. J., Emilio o de la educación,..., cit., p. 464. 


\section{BIBLIOGRAFÍA}

\section{Libros}

Cicerón, M. T.: Las Leyes, Traducción, introducción y notas por Álvaro D’ Ors, Instituto de estudios políticos, 1970.

De Vega García, P.: La reforma constitucional y la problemática del Poder Constituyente, ed. Técnos, Madrid, 2011.

Fondevila Marón, M., La disolución de la soberanía en el ámbito estatal. El proceso de integración europea. Precedido por J. Ruipérez Alamillo, "Prolegómenos al Estudio de la disolución de la soberanía del Pueblo en el proceso de integración europea, y algunas de sus consecuencias jurídicas y políticas», REUS, Madrid, 2014.

GonZÁlez Mariñas, P.: Las Diputaciones provinciales en Galicia: Del Antiguo Régimen al constitucionalismo, Diputación Provincial de La Coruña, A Coruña, 1978.

Heller, H.: Europa y el fascismo, Traducido del alemán por Francisco J. Conde, editorial Comares, Granada, 2006.

JellineK, G.: Teoría General del Estado, (1911, 2a edición), Prólogo y traducción de Fernando de los Ríos, ed. Fondo de Cultura económica, 2000.

Kelsen, H.: Teoría General del Estado, México, 1979, 15. ${ }^{a}$ ed.

Montesquieu: Del espíritu de las leyes, (1748), traducido por Pedro de Vega y Mercedes Blázquez Polo, editorial Tecnos, Madrid, 1985.

Rousseau, J. J.: Discurso sobre el origen y los fundamentros de la desigualdad entre los hombres y otros escritos, (1753), editorial Técnos, Madrid, 1987.

- Emilio o de la educación, (1762), traducido por Luis Aguirre Prado, editorial EDAF, 1985.

- El contrato social, (1762), traducido por Enrique López Castellón, Ediciones P. P. P., Madrid, 1985.

Ruipérez Alamillo, J.: Formación y determinación de las Comunidades Autónomas en el ordenamiento constitucional español, Tecnos, Madrid, 1996.

- La protección constitucional de la autonomía, editorial Tecnos, Madrid, 1998.

- La Constitución europea y la Teoría del Poder Constituyente (Algunas reflexiones críticas desde el Derecho político), Biblioteca Nueva S. L., Madrid, 2000.

- La Constitución del Estado de las Autonomías. Teoría constitucional y práctica política en el «federalising process» español, ed. Biblioteca Nueva S. L., Madrid, 2003.

- El constitucionalismo democrático en los tiempos de la globalización: Reflexiones rousseaunianas en defensa del Estado constitucional democrático y social, Universidad Nacional Autónoma de México, México, 2005.

- Libertad civil e ideología democrática, Universidad Nacional Autónoma de México, México, 2008. 
- Reforma vs. Revolución. Consideraciones desde la Teoría del Estado y de la Constitución sobre los límites materiales a la revisión constitucional, Porrúa, México, 2013.

\section{Artículos}

Arroyo GiL, A., «Autonomía Local. Una reflexión constitucional», XIII Congreso anual de la Asociación de Constitucionalistas de España: «La Organización Territorial del Estado, hoy», Zaragoza, 19 y 20 de diciembre de 2015

Belda Pérez-Pedrero, E.: «Condado de Treviño: La STC 99/86, de 11 de Julio, doce años después», La Justicia constitucional en el Estado democrático, Cortes de Castilla La Mancha, Tirant lo Blanch, Valencia, 2000.

Cano Rubio, M. D.: «Cómo el liberalismo económico influye en la regulación socio-económica de un país: El papel de las Diputaciones provinciales», Sobre un bito jurídico, La Constitución de 1812. Reflexiones actuales, estados de la cuestión, debates historiográficos, Universidad de Jaén, Jaén, 2012.

Carbonell Porras, E.: «La división del territorio en provincias y su evolución», Sobre un bito jurídico, La Constitución de 1812. Reflexiones actuales, estados de la cuestión, debates historiográficos, Universidad de Jaén, Jaén, 2012.

Cabanas Veiga, M.: «Las Diputaciones Provinciales gallegas en la recesión económica actual y la crisis del principio de autonomía local», AFDUDC, $\mathrm{n}^{\circ} 18$, 2004 .

— «La reforma constitucional del 2011 y la Teoría del Poder Constituyente», ADFUDC, $\mathrm{n}^{\circ} 18,2013$.

Carbonell Porras, E.: «La división del territorio en provincias y su evolución», Sobre un bito jurídico, La Constitución de 1812. Reflexiones actuales, estados de la cuestión, debates historiográficos, Universidad de Jaén, Jaén, 2012.

De Vega García, P.: «Significación constitucional de la representación política», Revista de Estudios políticos (Nueva Época), número 44, marzo-abril, 1985.

— «La crisis de la representación política en la democracia de partidos», Tendencias contemporáneas del Derecho electoral en el mundo. Memoria del II Congreso internacional de Derecho electoral, UNAM, México, 1993.

- «En torno a la crisis de las ideas de representación y de legitimidad en la democracia actual», Temas de Derecho Público 42, Universidad Externado de Colombia, Bogota, 1996.

- «La Democracia como proceso. Algunas reflexiones desde el presente del republicanismo de Maquiavelo», eds: A. Guerra y J. F. y otros. Alternativas para el siglo XXI. I Encuentro en Salamanca, Sistema, Madrid, 2003.

- «La reforma constitucional como defensa de la Constitución y la Democracia», Ponencia presentada a las II Jornadas de Derecho Constitucional: "Reforma de la Constitución», Fundación Jimenez Abad de Estudios Parlamentarios y del Estado 
Autonómico y Centro Asociado de la UNED de Barbastro, Huesca, 27 y 28 octubre 2006.

Fondevila Marón, M.: «Derecho a decidir y soberanía. A propósito de la STC 42, 2014, de 25 de marzo», TRC., núm. 34, 2014.

Hernández Bravo de Laguna, J.: «Partidos políticos, Estado y Derecho: de la hostilidad a la teoría», Anales de la facultad de Derecho, nº 9, 2002.

Míguez Machado, L.: «Galicia y la reforma de la Administración Local», Revista Xurídica da Universidade de Santiago de Compostela, no Extra 1, noviembre, 2013

Pisarello, G.: «Constitución y Gobernabilidad: Razones de una democracia de baja intensidad», Las sombras del sistema constitucional español, Coor. por J. R. Capella, Editorial Trotta, Madrid, 2003.

RAmiro, L.: «Del privilegio constitucional de los partidos a la promoción del multipartidismo moderado. Constitución, sistema electoral y financiación de los partidos políticos en España», Las sombras del sistema constitucional español, Coor. por J. R. Capella, editorial Trotta, Madrid, 2003.

Rodríguez Álvarez, J. M.: «Estructura institucional y organización local en España: fragmentación municipal, asociacionismo confuso, grandes ciudades y provincias supervivientes», Política y Sociedad, vol. 47 núm. 3, 2010.

RodrigueZ-Arana MuÑoz, J.: «El Gobierno y la Administración Local en españa: Sobre las alteraciones de los términos municipales con especial referencia al caso gallego», AFDUDC, 2013.

Ruipérez Alamillo, J.: «La Constitución y su estudio. Un episodio en la forja del Derecho Constitucional europeo: Método jurídico y régimen político en la llamada Teoría Constitucional de Weimar», en C. León Bastos y V. A. Wong Meraz (coords.) y otros, Teoría de la Constitución. Estudios jurídicos en homenaje al Dr. Jorge Carpizo en Madrid, México, 2010.

Salvador Crespo, M.: «Las Diputaciones provinciales en la Constitución de Cádiz de 1812», Sobre un hito jurídico, La Constitución de 1812. Reflexiones actuales, estados de la cuestión, debates historiográficos, Universidad de Jaén, Jaén, 2012.

SÁnchez Blanco, A: «Ajustes territoriales en las Comunidades Autónomas. Derechos institucionales y Derechos de las Comunidades sociales. La sentencia del Tribunal Constitucional 99/1986 relativa al condado de Treviño», RVAP, Facultad de Derecho de Salamanca, nº 16, 1986

\section{Legislación.}

Constitución de 1978.

Constitución de 1931.

Ley Orgánica 4/1983, de 25 de febrero, de Estatuto de Autonomía de Castilla-León (Vigente hasta el 30 de noviembre del 2007.) 
Ley Orgánica 14/2007, de 30 de noviembre, de reforma del Estatuto de Autonomía de Castilla y León.

Ley Orgánica 3/1979, de 18 de diciembre, de Estatuto de Autonomía para el País Vasco.

Carta Europea de la Autonomía Local.

Ley 7/1985, de 2 de abril, reguladora de las Bases del Régimen Local.

Ley 30/1992, de 26 de noviembre, de Régimen Jurídico de las Administraciones Públicas y del Procedimiento Administrativo Común (vigente hasta el 1 de junio de 2015).

Ley de 17 de julio de 1958, de Procedimiento Administrativo.

Ley 1/1998, de 4 de junio, de Régimen Local de Castilla y León (vigente hasta el 20 de septiembre de 2014).

\section{Sesiones parlamentarias.}

Diario de Sesiones del Congreso de los Diputados. Pleno y Diputación, año 2014, X Legislatura, núm. 240, Sesión Plenaria núm. 225, celebrada el martes 18 de noviembre de 2014.

Diario de Sesiones del Congreso de los Diputados, 1983, II Legislatura, núm. 9. Sesión 26 de enero de 1983.

\section{Jurisprudencia.}

STC de 12 de noviembre de 1981.

STC de 11 de julio de 1986.

STC de 19 de octubre de 1989.

Title:

TREVIÑO: BETWEEN THE STATUTORY RESERVE AND THE ORGANIC LAW

\section{Summary:}

I. Introduction. II. Approach of the constitutional problems in attention to the case. III. Proposals and parliamentary resolution. IV. Statutory amendment or Organic law? V. Conclusion.

\section{Resumen:}

Desde el medievo hasta nuestros días, no han cesado los argumentos a favor y en contra de la agregación de Treviño a la provincia alavesa. Así, el presente trabajo analiza los diferentes argumentos parlamentarios y jurisprudenciales desde su perspectiva histórico-política, con la finalidad de dilucidar la adecuación de los mismos al ordenamiento 
constitucional y estatutario aplicable a dicho supuesto. Así, será preciso realizar una crítica acerca de los problemas de algunas hipótesis planteadas y aportar una posible solución que permita poner fin a un contencioso que aparenta visos de perpetuidad.

\title{
Palabras clave:
}

Treviño, Comunidades Autónomas; reforma estatutaria; secesión; Municipios; referéndum; alteración territorial.

\begin{abstract}
:
From the Middle Ages to the present day, arguments in favour and against the addition of Treviño to the Spanish province of Álava have not stopped. Thus, this paper examines the different parliamentary and judicial arguments from their historical and political perspective in order to elucidate their adaptation to the constitutional and statutory system applicable to such case. So, it will be necessary to make a review of the problems that some of the suggested hypothesis have and to offer a possible solution that brings an end to a seemingly endless conflict.
\end{abstract}

\section{Key words:}

Treviño; Autonomous Communities; Statutory amendment; Secession; Town Councils; Referendum; Territorial alteration. 